\title{
Probing the nanoscale architecture of clay minerals
}

\author{
Based on the 2004 George Brown Lecture
}

\author{
C. T. JOHNSTON*
}

Crop, Soil and Environmental Sciences, Purdue University, 915 W. State Street, West Lafayette, IN 47907-2054, USA

(Received 16 November 2009; revised 8 June 2010; Editor: David Bish)

\begin{abstract}
In recent years, experimental and theoretical methods have provided new insights into the size, shape, reactivity, and stability of clay minerals. Although diverse and complex, the surface chemistry of all clay minerals is defined spatially on a common scale of nanometres. This review is organized around the nanoscale architecture of clay minerals examined at several different length scales. The first, and perhaps most important, is the length scale associated with $\mathrm{H}$ bonding in clay minerals. $\mathrm{H}$ bonding interactions define the size and shape of $1: 1$ phyllosilicates and dominate the surface chemistry of many clay minerals. Structural and surface $\mathrm{OH}$ groups contained within and on the surface of clay minerals provide a type of 'molecular reporter group' and are sensitive to subtle changes in their local environment. Examples of $\mathrm{OH}$-reporter group studies in clay minerals, and the spatial scales at which they provide diagnostic information, are examined. The second length scale considered here is that associated with clay-water and clay-organic interactions. Inorganic and organic solutes can be used to explore the surface chemistry of clay minerals. Similar to the use of reporter groups, molecular probes have diagnostic properties that are sensitive to changes in their molecular environment. Clay-water interactions occur at a length scale that extends from the size of the $\mathrm{H}_{2} \mathrm{O}$ molecule $(\sim 0.3 \mathrm{~nm})$ to the larger scales associated with clay-swelling $(>10 \mathrm{~nm})$. Similarly, clay-organic interactions are also defined, in part, on the basis of their molecular size, in addition to the type of chemical bonding interactions that take place between the organic solute and the clay surface. Examples illustrating the use of clay-water and clay-organic solute interactions as molecular probes are presented. The largest scale to be considered is that of the particles themselves, with scales that approach micrometres. Recent developments in the synthesis and characterization of ultrathin hybrid films of clay minerals provide complementary information about the nature and distribution of active sites on clay minerals, as well as providing new opportunities to exploit the surface chemistry of clay minerals in the design of functional materials.
\end{abstract}

KEYwORDS: clay mineral, nanoscale architecture, surface chemistry, nanomaterials, $\mathrm{OH}$ groups, hydrogen bonding, clay-water interactions, clay-organic interactions.

Clay minerals are naturally occurring and synthetic nanomaterials whose primary particles range in size from Ångstroms to micrometres (Bergaya \& Lagaly, 2006). Because of their small size, expansive surface areas, anisotropic shape and reactive surfaces, the

* E-mail: clays@purdue.edu

DOI: $10.1180 /$ claymin.2010.045.3.245 importance of these ubiquitous nanoparticles has been recognized in a wide range of disciplines. Furthermore, they are spatially distributed from deep within the Earth's crust to Martian landscapes and span length scales that extend from a few nanometres to processes that are evident from satellite-based observation of the Earth. Clay minerals are the most abundant naturally occurring nanomaterials known to humans with densities of particles that can approach $10^{22}$ clay particles $/ \mathrm{m}^{3}$ in 
soil and subsurface environments as well as comprising a significant fraction of the nanoparticles found in the atmosphere.

More important than their overall abundance, clay minerals represent one of the dominant environmental interfaces found in the 'pedo-lithohydro-sphere' which control and direct most physical, biological and chemical reactions. To this end, clay minerals play a uniquely prominent role in the freshly minted disciplines of nanogeoscience (Hochella, 2006, 2008) and the science of the critical zone (Richter, 2007; Wilding \& Lin, 2006). In soil and subsurface environments, essentially all inorganic and organic solutes are attracted to, transformed on, or repelled from clay minerals. In geotechnical areas, the presence of clay minerals controls structural stability of soils and influences liquefaction. As clay minerals often represent a significant fraction of the hydrous mineral phases found in the Earth's mantle, they influence dynamic processes of water regulation in the mantle and their presence in subduction zones are thought to play a role in triggering deep-focus earthquakes. In recent years, clay-based applications in the fields of nanoscience and nanotechnology have exponentially grown research areas with the goal of producing new functional nanomaterials in which low cost- and high added value-clay minerals are attractive constituents (Ras et al., 2007b). Common to all of these disciplines are the reactions that occur at the clay-water interface on a scale from Angstroms to nanometres.

The nanometre length scales associated with clay minerals along at least one dimension is both the reason for their utility and a challenge to their characterization. Since the pioneering work of Hendricks and Pauling, details about their atomic structure and composition have been steadily revealed over the past eight decades (Hendricks, 1929; Pauling, 1930). Classic and modern synchrotron-based X-ray studies have played a prominent role in revealing detailed information about the atomic structures of clay minerals and local structures of adsorbed species with sub-Ångstrom resolution (Brown et al., 1999, 2005). However, it is the size domain slightly larger than Angstroms that continues to present experimental, theoretical and numerical challenges. It is at the scale of nanometres, which defines active sites on clay surfaces, where both clay-water surface interactions and particle-particle interactions occur, to name two important areas.
This review will examine the surface structure and reactivity of clay minerals at several different length scales as depicted in Fig. 1. These span from the sub-Ångstrom scale interactions of hydroxyl groups to the approximate size of particles $(>1000 \mathrm{~nm})$ and will rely mainly on spectroscopic observations. Three size domains are considered, beginning with the smallest length scale, that of hydrogen bonding ( $\mathrm{H}$ bonding). The chemistry of the hydrogen atom extends far beyond its size $(\sim 0.1 \mathrm{~nm})$ and its elemental abundance in the Earth's crust $(\sim 0.15 \%)$, playing a central role in aqueous geochemistry and defining the surface chemistry of clay minerals. The scale of $\mathrm{H}$ bonding is most commonly defined on the basis of interatomic $\mathrm{O} \cdots \mathrm{O}$ distances occurring within the range of 0.25 to $0.35 \mathrm{~nm}$. The next scale to be considered is that associated with clay-water and clay-organic interactions (Fig. 1). At these length scales, multiple molecular mechanisms are operative (including $\mathrm{H}$ bonding) and span from the size of the $\mathrm{H}_{2} \mathrm{O}$ molecule and small polar organic solutes $(0.3$ $\mathrm{nm})$ to that of large biological molecules (e.g. proteins) and the limit of clay-water swelling (10 $\mathrm{nm})$. Interactions at these smaller length scales also impact how clay particles interact with other particles. The operative length scales for these interactions extend from the thickness of a delaminated smectite particle $(1 \mathrm{~nm})$ to the basal dimensions of large clay particles and aggregates with dimensions that commonly exceed one $\mathrm{mm}$. This review will conclude with one illustrative example of clay particle-particle interactions at this 'particle' scale (Fig. 1).

\section{HYDROGEN BONDING $(<0.35 \mathrm{~nm})$}

\section{Structural and surface hydroxyl groups}

All clay minerals contain structural and surface hydroxyl $\mathrm{OH}$ groups. Structural $\mathrm{OH}$ groups are those contained within the crystal structure of the clay particle and surface $\mathrm{OH}$ groups are those $\mathrm{OH}$ groups on the external basal or edge surfaces of the clay particle. These $\mathrm{OH}$ groups, and the $\mathrm{H}$ bonding interactions in which they participate, dominate the surface chemistry of many clay minerals (Davis \& Kent, 1990; Johnston \& Tombacz, 2002; Sposito, 1984). For 1:1 phyllosilicates and hydrous oxides, the type and strength of the interlayer $\mathrm{H}$ bonds of the structural $\mathrm{OH}$ groups govern their size, shape and geochemical stability. In addition, all clay 
(length scale of nanometres)

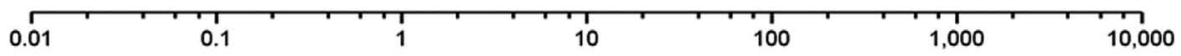

Hydrogen bonding
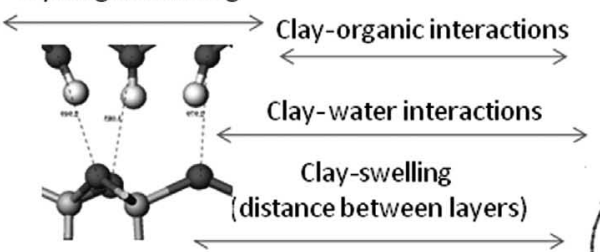

Polytypes ID \& Structural disorder

Particle morphology

Functional materials

High pressure phase transitions

Surface modification Hybrid materials

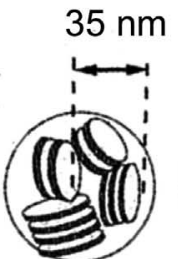

Distance between

charge sites in clay interlayers
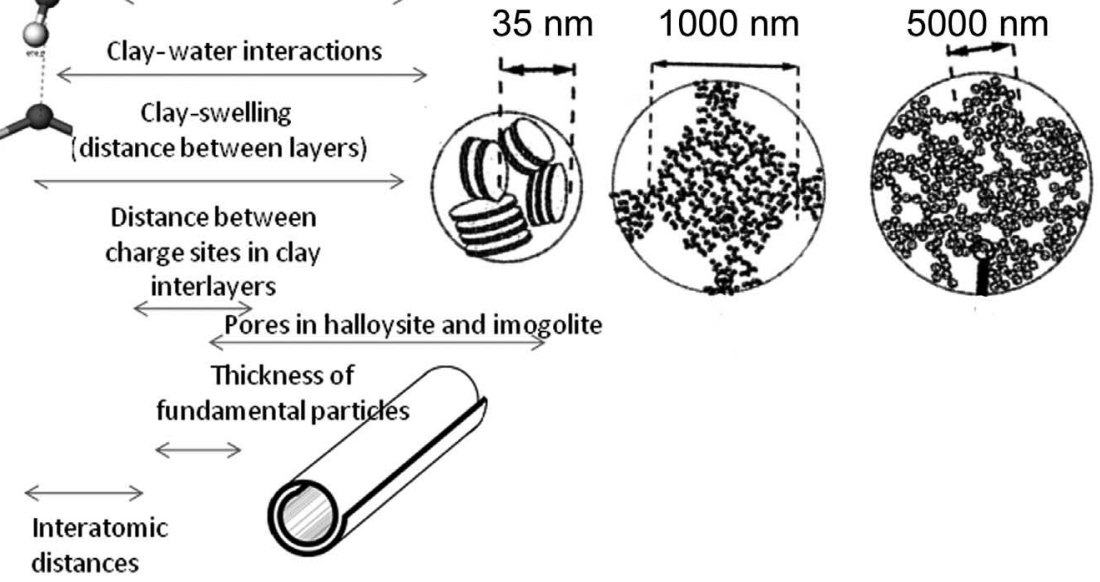

Size of secondary particles

Size of primary particles

\begin{tabular}{l|l|l} 
Pore size $\quad$ Microscopic pores & Mesoscopic pores & Macroscopic pores
\end{tabular}

FIG. 1. Length scales associated with the structure and surface chemistry of clay minerals

minerals have surface $\mathrm{OH}$ groups located on basal surfaces, broken edges, steps and related defect sites. Basal surface $\mathrm{OH}$ groups, such as the $\mathrm{OH}$ groups on the terminal $\mathrm{Al}$ octahedral sheet of kaolinite, are coordinated to metal atoms whose coordination environment is complete and are charge-neutral. These types of hydroxyl surfaces are also common to many hydrous oxides, such as gibbsite (Johnston \& Tombacz, 2002; Schoonheydt $\&$ Johnston, 2007). The surface $\mathrm{OH}$ groups located at broken edges, steps and defect sites, on the other hand, are under-coordinated and reactive. Consequently, they generally carry either a positive or a negative charge depending on the type of metal ion they are coordinated to, and the $\mathrm{pH}$ of the ambient aqueous solution they are in contact with (Schindler et al., 1976; Schoonheydt \& Johnston, 2007; Stumm, 1992). These under-coordinated surface $\mathrm{OH}$ groups are among the most abundant and reactive surface functional groups found in soil and subsurface environments (Sposito, 1984).
Hydrogen bonds ( $\mathrm{H}$ bonds) are defined on the basis of their bond length, geometry and bond strength with strong $\mathrm{H}$ bonds having interatomic $d(\mathrm{O} \cdots \mathrm{O})$ distances of $<0.27 \mathrm{~nm}$ and weak $\mathrm{H}$ bonds defined by distances of $>0.27 \mathrm{~nm}$ (Libowitzky, 1999; Pauling, 1960; Pimentel \& McClellan, 1960). The positions of the $\mathrm{OH}$ stretching and bending vibrations observed in the vibrational spectra of clay minerals (IR, Raman and inelastic neutron scattering) provide the most sensitive measure of $\mathrm{H}$ bonding. In particular, the vibrational frequencies associated with the stretching motion of the structural hydroxyl groups are remarkably sensitive to subtle changes in their local environment. This is illustrated in Fig. 2 by the distance-frequency relation obtained from 65 minerals showing the change in $v(\mathrm{OH})$ frequency versus the interatomic $d(\mathrm{O} \cdots \mathrm{O})$ distance. These data show that a change in the interatomic distance of $0.1 \mathrm{~nm}$ results in a change in frequency of over $2500 \mathrm{~cm}^{-1}$ (Libowitzky, 1999). In reference to Fig. 1, the 


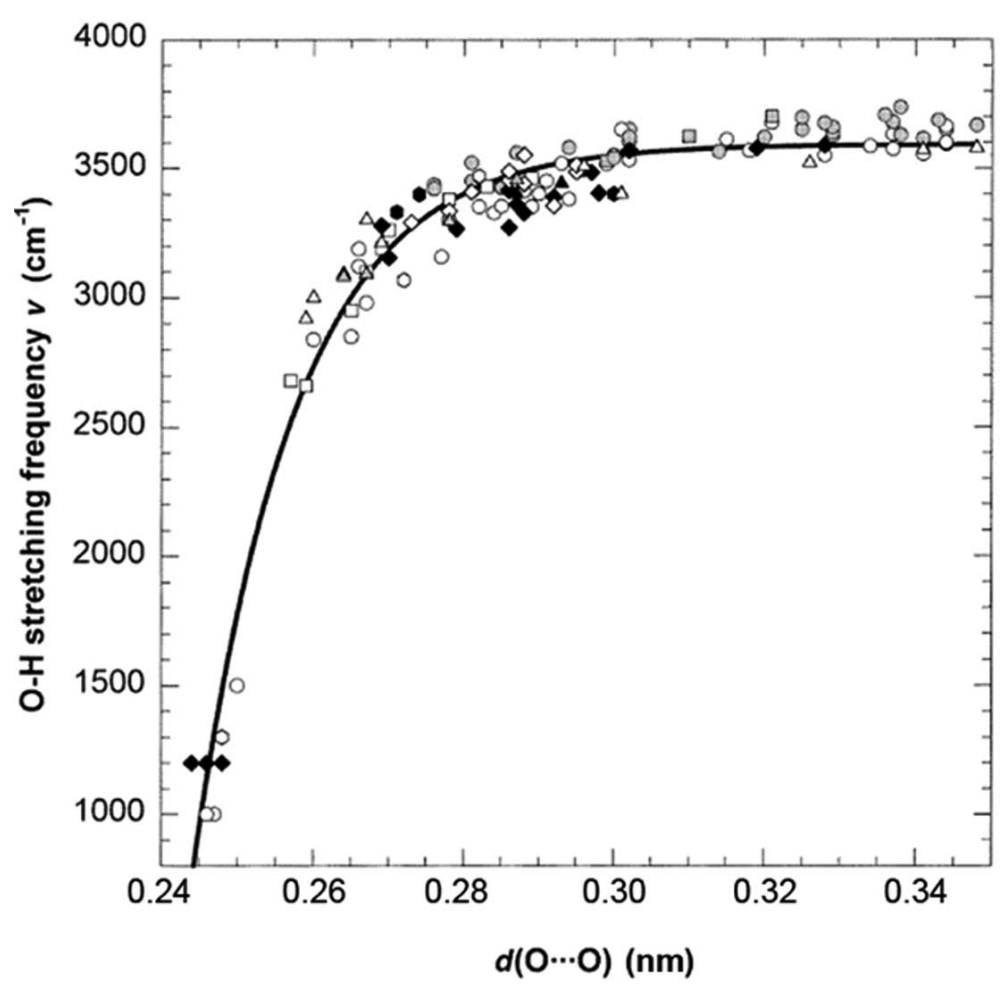

FIG. 2. Distance frequency relationship for 125 data pairs corresponding to different classes of minerals (shown by different symbols) by plotting the position of the $\mathrm{v}(\mathrm{OH})$ band against the interatomic $\mathrm{O} \cdots \mathrm{O}$ distance (i.e. the O-H $\cdots$ O hydrogen bonding distance). From Libowitzky (1999), used with permission.

'primary scale' at which $\mathrm{H}$ bonding interactions occur is $<0.35 \mathrm{~nm}$. However, as will be the case for other bonding interactions, $\mathrm{H}$ bonding influences colloidal phenomena at much larger scales.

\section{Structural OH groups: distance-frequency relationship for subgroup minerals}

To illustrate this relationship for clay minerals, consider the structural $\mathrm{OH}$ groups of the kaolin subgroup minerals kaolinite, dickite and nacrite. The crystal structure of kaolinite projected along [010] is shown in Fig. 3, showing the three unique inner-surface hydroxyl groups labelled $\mathrm{A}-\mathrm{C}$ which form long interlayer hydrogen bonds with $\mathrm{O} \cdots \mathrm{O}$ distances ranging from 0.295 to $0.308 \mathrm{~nm}$. For example, kaolinite is one specific polytype of the kaolin subgroup that corresponds to an overall minimum in the combined distances of the three unique interlayer $\mathrm{O}(\mathrm{H}) \cdots \mathrm{O}$ couples. The other polytypes of kaolin subgroup minerals, dickite and nacrite, share the same fundamental layer composi- tion and structure as kaolinite. However, they differ in how subsequent layers are stacked on top of each other, with each polytype represented by a unique set of interlayer $\mathrm{O}(\mathrm{H}) \cdots \mathrm{O}$ pairings. The position of the $v(\mathrm{OH})$ bands measured using vibrational spectroscopy can distinguish among the polytypes and is useful to illustrate the sensitivity of $v(\mathrm{OH})$ bands of the structural $\mathrm{OH}$ groups to structural differences. Fourier transform infrared (FTIR) spectra of the three polytypes obtained at room and low temperature $(<20 \mathrm{~K})$ are shown on the left side of Fig. 4. The slope of the distance-frequency curve for kaolinite, dickite and nacrite (Fig. 4; right side) is $4000 \mathrm{~cm}^{-1} / \mathrm{nm}$, or $4 \mathrm{~cm}^{-1} / \mathrm{pm}$. This relationship reveals that a difference in the interlayer $\mathrm{O} \cdots \mathrm{O}$ distance of $0.001 \mathrm{~nm}$ results in a shift in band position of $4 \mathrm{~cm}^{-1}$ (Johnston et al., 1993, 2008; Johnston \& Stone, 1990). Similar distance-frequency relationships have been established for gibbsite using Raman and FTIR spectroscopy (Wang \& Johnston, 2000). These structural (and surface) $\mathrm{OH}$ groups provide a type of reporter 


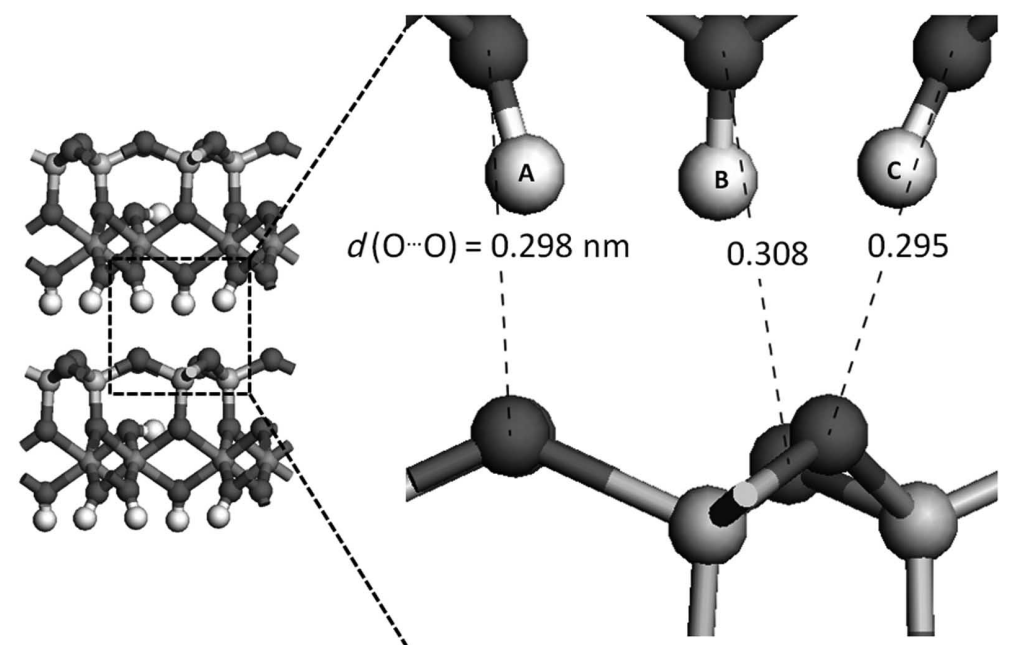

FIG. 3. The crystal structure of kaolinite projected along [010] is shown on the left side, showing the three crystallographically distinct 'inner-surface' OH groups. An expanded view of these three OH groups, labelled $\mathrm{A}-\mathrm{C}$, and their interlayer $\mathrm{O} \cdots \mathrm{O}$ distances in $\mathrm{nm}$ is shown on the right side. The crystal structure is that of Bish

(1993).

group that signal perturbations in their local environment. Reporter groups are part of the molecular structure of the clay particle, or occur at the external surface of the clay particle, and have diagnostic properties, such as $v(\mathrm{OH})$ bands, that are influenced by changes within the clay structure or by reactions at the interface (Gale, 2000; Johnston et al., 1993). The use of structural and surface $\mathrm{OH}$ groups is emphasized here; however, other examples of reporter groups including NMR-active structural nuclei such as ${ }^{27} \mathrm{Al}$ and ${ }^{29} \mathrm{Si}$ (Altaner et al., 1988), or structural $\mathrm{Fe}$ in Mossbauer spectroscopy (Heller-Kallai \& Rozenson, 1981) are commonly used as well.

\section{Structural OH groups: layer stacking disorder of kaolin subgroup minerals}

Structural and surface $\mathrm{OH}$ groups have been used as reporter groups to study structural disorder in kaolin subgroup minerals. A typical crystal of kaolinite has a thickness of the order of 50 to $100 \mathrm{~nm}$. Since the fundamental thickness of a kaolinite layer is $0.7 \mathrm{~nm}$, this thickness represents approximately 70 to 200 individual layers stacked on top of each other. In well-ordered kaolinite, all the layers are stacked on top of each other in the same way. In disordered kaolins, however, layer stacking 'mistakes' occur and this has been the subject of extensive review (Bookin et al., 1989; Brindley \& Robinson, 1946; Murray, 1954; Plançon \& Tchoubar, 1977a,b). The only quantitative models available at present to assess layer stacking disorder in kaolin subgroup minerals are based on $\mathrm{X}$-ray diffraction. X-ray methods are intrinsically insensitive to structural differences involving the $\mathrm{H}$ atom and are consequently limited in their ability to detect layer stacking disorder (Bookin et al., 1989; Johnston et al., 2008; Plançon, 2001; Plançon et al., 1988; Plançon \& Tchoubar, 1977b). From a structural point of view, each type of 'mistake' or layer stacking disorder results in a different, unique set of interlayer $\mathrm{O} \cdots(\mathrm{H}) \mathrm{O}$ pairings. Upon cooling kaolin sub-group minerals to near liquid-He temperatures, FTIR spectra of disordered kaolins reveal an additional set of 'disorder-indicator' bands (Bish \& Johnston, 1993; Frost \& Kloprogge, 2000; Prost, 1984; Prost et al., 1987). These results are in good agreement with recent high-resolution transmitted electron microscopy (HRTEM) and selected area electron diffraction (SAED) studies of kaolin subgroup minerals by Kogure and coworkers who have observed stacking faults directly (Kameda et al., 2005, 2008; Kogure et al., 2010; Kogure \& Inoue, 2005a,b). This is illustrated by low-temperature FTIR spectra of two Brazilian kaolins shown in Fig. 5 along with SAED images of the Capim sample (Johnston et al., 2008). 

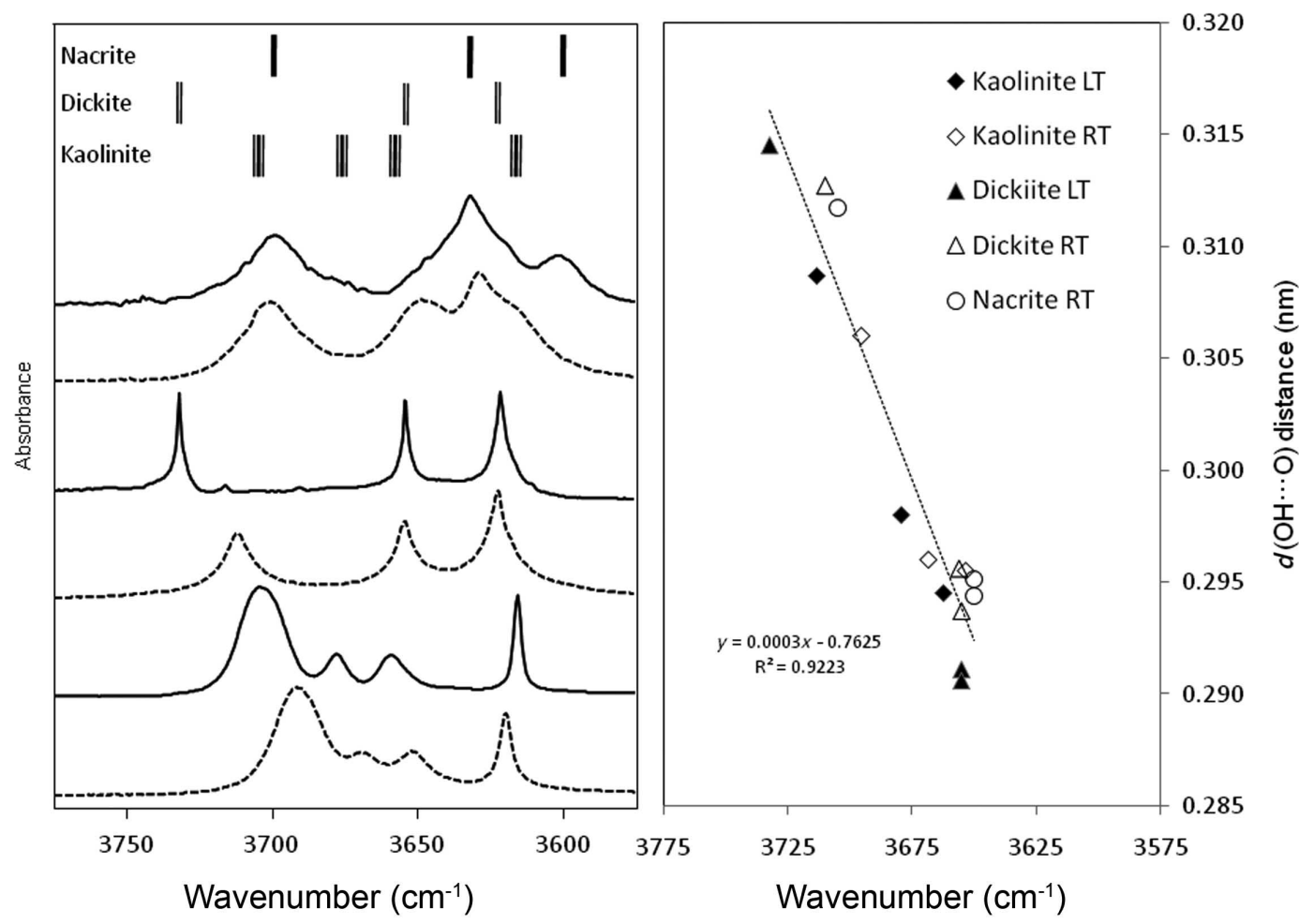

FIG. 4. FTIR spectra of nacrite, dickite and kaolinite at room (300 K represented by dashed lines) and low temperature $(<20 \mathrm{~K}$ represented by solid lines) in the $v(\mathrm{OH})$ region. The vertical lines for each of the polytypes shown in the upper right portion of the figure illustrate the diagnostic frequencies for each polytype. The corresponding distance frequency relationship for these three polytypes is shown on the right side with the interatomic $d(\mathrm{O} \cdots \mathrm{O})$ distance plotted on the $\mathrm{y}$ axis versus the observed frequency of the corresponding $v(\mathrm{OH})$ band. These curves are adapted from Johnston et al. (2008).

In addition to the $v(\mathrm{OH})$ bands of kaolinite, these spectra reveal the presence of $v(\mathrm{OH})$ bands that are coincident with those of dickite (shown by the dashed line) and nacrite (shown by the light grey line). The FTIR spectra cannot distinguish between layer stacking disorder and the presence of discrete dickite and nacrite phases. However, the SAED pattern for this sample indicates that this type of disorder does not result from a discrete phase but rather interstratification of different types of layer stacking within a given particle. The reciprocallattice rows in the pattern (Fig. 5a) were streaked along the $c^{*}$ direction, indicating that this crystal contained a mixture of stacking sequences from different subfamilies of 1:1 phyllosilicates (Bailey, 1988; Kogure et al., 2001). Layer-stacking disorder is an important property of kaolin group minerals related to industrial applications. In addition, layer- stacking disorder characterizes sandstone diagenesis as kaolinite is transformed to dickite with increasing depth and temperature (Beaufort et al., 1998; Lanson et al., 2002). The combined application of low-temperature FTIR spectroscopy and high-resolution electron methods are providing new insight about layer stacking disorder in kaolin subgroup minerals over the domain of a single layer (i.e. $0.7 \mathrm{~nm})$ to many layers $(\sim 50 \mathrm{~nm}-$ see fig. 5 in Kogure \& Inoue, 2005b).

\section{Structural OH groups: clay minerals at high pressure}

The spectral changes observed in Figs 4 and 5 resulted from an overall contraction of the crystal lattice induced upon cooling (Bish, 1993; Bish \& Johnston, 1993) and a concomitant change in the 

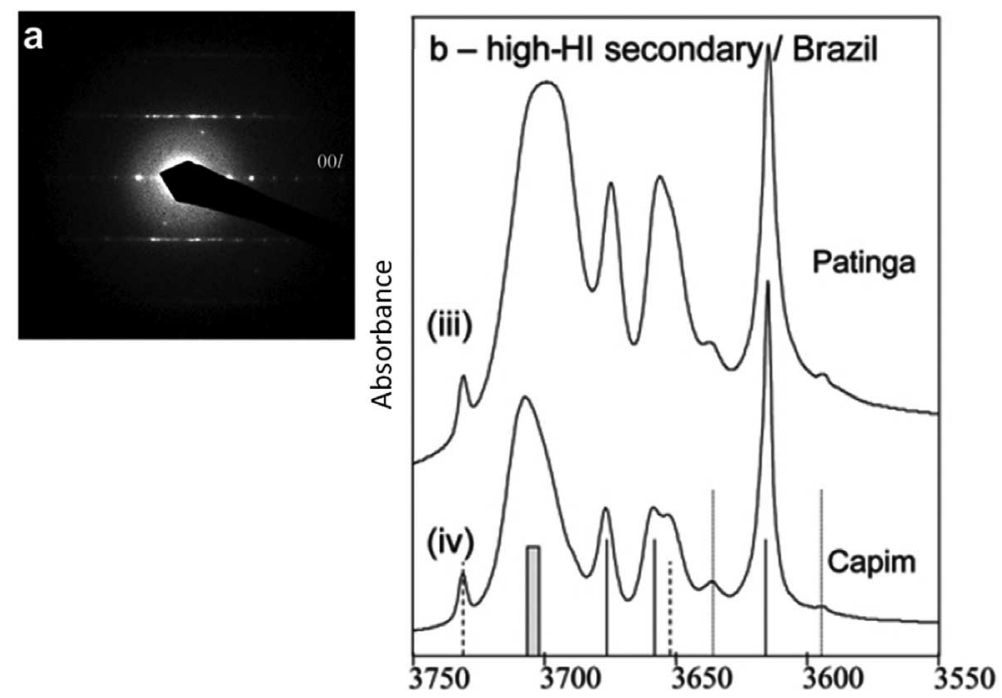

FIG. 5. Low-temperature FTIR spectra of two high-HI kaolins from Brazil (Patinga \& Capim). The $v(\mathrm{OH})$ bands shown by the dashed and light gray vertical lines are coincident with those of dickite and nacrite. Selected-area electron diffraction (SAED) pattern from the Capim kaolin sample is shown on the left. The pattern is indicative of interstratification of different subfamilies, supposedly nacrite and kaolinite-dickite. From Johnston et al.

(2008), used with permission.

interlayer $\mathrm{O} \cdots \mathrm{O}$ distances (Johnston et al., 2008). Similar structural changes can also be induced by a change in pressure. Using a high-pressure diamond anvil cell (DAC) the Raman spectra and crystal structure of dickite were obtained as a function of pressure (Dera et al., 2003; Johnston et al., 2002b). Raman spectra and crystal structures were obtained at pressures up to $6.5 \mathrm{GPa}(65 \mathrm{kbar})$ and are shown in Fig. 6. The crystal structure of dickite determined at high pressure (Dera et al., 2003) revealed interlayer compression and a layer shift that was responsible for the pronounced changes observed in the $v(\mathrm{OH})$ bands as a function of increasing pressure. The pressure dependence of the $v(\mathrm{OH})$ bands signalled the presence of a structural phase change (Johnston et al., 2002b) which provided the basis for a subsequent detailed structural study (Dera et al., 2003). Although the structural changes were small, with interlayer $\mathrm{O} \cdots \mathrm{O}$ distances changing less than $0.02 \mathrm{~nm}$, the shifts of the $v(\mathrm{OH})$ bands were significant. Related data have been reported for gibbsite (Huang et al., 1996, 1999; Johnston et al., 2002b), brucite (Shinoda, 1998), and vermiculite (Holtz et al., 1993). For a review of high- pressure methods applied to clay minerals see Butler \& Frost, 2006.
Structural OH groups: particle size and shape analysis

Details about the influence of particle size and shape on vibrational spectra of hydrous minerals are slowly coming into focus. For the past 30 years, there has been some difficulty in reconciling differences observed between IR and Raman spectra of certain types of kaolin group minerals in the $v(\mathrm{OH})$ region (Johnston et al., 1985; Michaelian, 1986; Shoval et al., 1999a,b; Wiewiora et al., 1979). Because of the low symmetry of kaolin group minerals, the $v(\mathrm{OH})$ bands are expected to be both IR- and Raman-active. However, a 'fifth' band appears in the Raman spectra of certain kaolinite samples that does not have an apparent IR-counterpart. Experimental insight into this problem was provided by polarized single crystal Raman and FTIR spectra obtained from oriented single crystals of kaolinite and dickite (Frost \& Kloprogge, 2000; Johnston et al., 1990, 1998; Shoval et al., 2002), where polarized spectra could be obtained from crystal edges as well as normal to the face of the pseudo-hexagonal shaped crystals. However, it was not until Farmer successfully applied theoretical considerations in the form of LO-TO splitting to account for these differences (Farmer, 1998, 2000) 

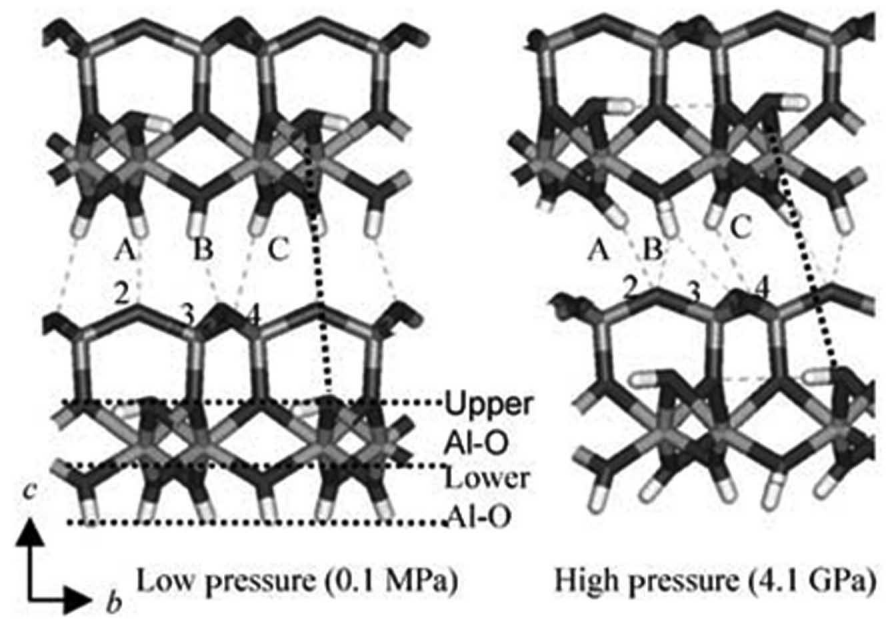

High pressure $(4.1 \mathrm{GPa})$
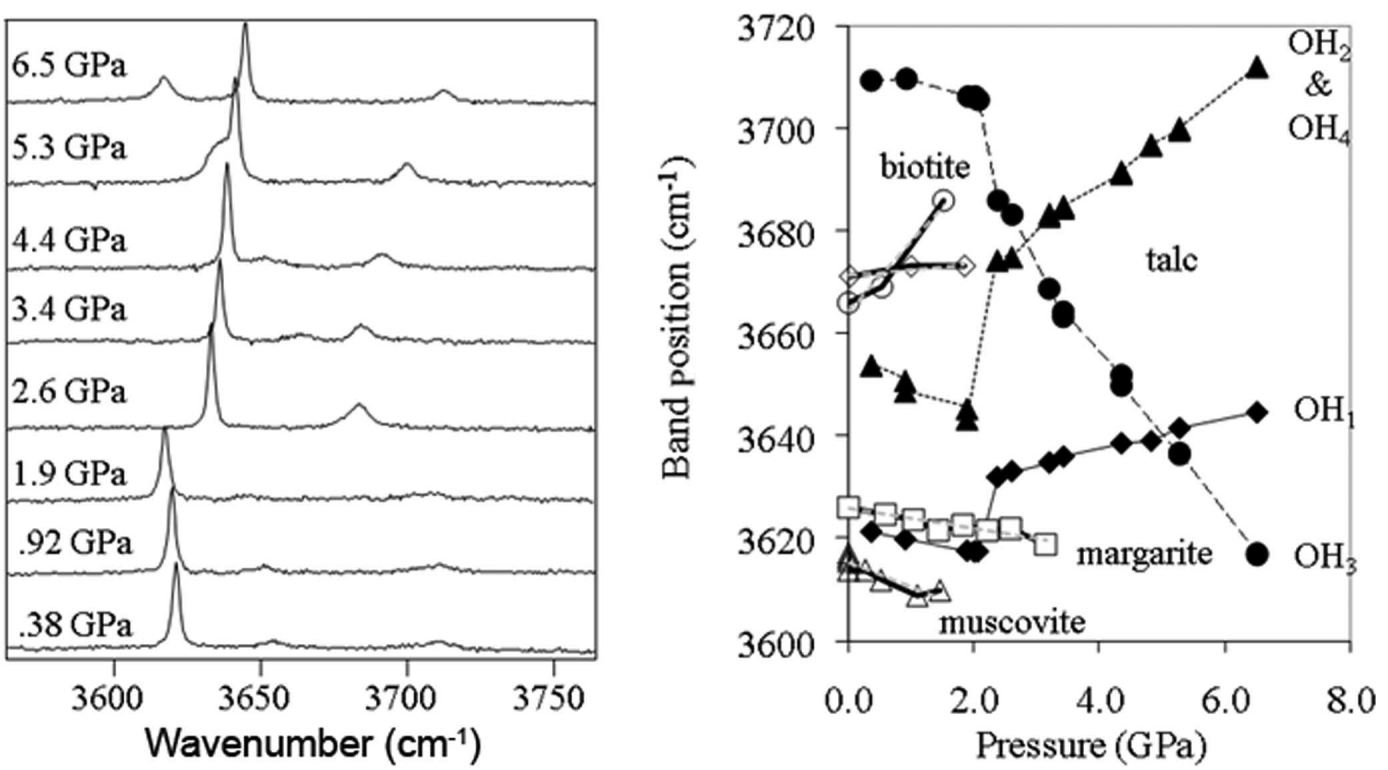

FIG. 6. In situ high-pressure single-crystal Raman spectra of dickite from 0.38 to $6.5 \mathrm{GPa}$ (lower left). Positions of the $v(\mathrm{OH})$ bands as a function of pressure (lower right). From Johnston et al. (2002b), used with permission. Crystal structures of dickite obtained at $0.1 \mathrm{MPa}$ and 4.0 GPa from Dera et al. (2003) and available from the American Mineralogist Crystal Structure Database (Downs \& Hall-Wallace, 2003).

that a satisfactory explanation was achieved. Subsequently, particle size and shape effects have been modelled successfully using density functional theory (Balan et al., 2001, 2005, 2006, 2007). The effect is a band shift related to the electrostatic charges occurring at the surface of the polarized dielectric particles. For platy crystals, bands at the TO and LO frequencies can be resolved (Farmer, 1998, 2000). However, a distribution of band positions resulting from the corresponding depolarization field is expected when particles are not ellipsoidal or when various particle shapes occur in the sample. Parallel experimental and theoretical developments have been successfully applied to gibbsite (Balan et al., 2006; Wang \& Johnston, 2000), where particle size and shape have been shown to influence the $v(\mathrm{OH})$ bands of gibbsite (Phambu et al., 2000). 


\section{Surface OH groups}

Up to this point, we have focused our attention on $\mathrm{H}$ bonding interactions of structural $\mathrm{OH}$ groups which are contained within the clay structure. In addition, all clay minerals have surface $\mathrm{OH}$ groups at broken edges resulting from under-coordinated metal ions that have reacted with water. Depending on the nature of the metal ion, these groups can be very reactive, have high site densities $\left(\sim 2.2\right.$ groups $\left./ \mathrm{nm}^{2}\right)$ and play a dominant role in the rheological behaviour of clay minerals in contact with water. From an experimental standpoint, these groups are difficult to study because they represent only a small fraction of the total hydroxyl content of a clay particle. In addition, these groups are $\mathrm{H}$ bonded to interfacial water and the corresponding $v(\mathrm{OH})$ bands are broad and overlap with those of $\mathrm{H}_{2} \mathrm{O}$. To overcome this problem a range of experimental approaches has been attempted. Nonlinear optical methods, such as second harmonic generation (SHG) or sum frequency generation (SFG), provide an elegant, although complex approach (Du et al., 1994a,b; Eisenthal, 1996; Jena \& Hore, 2009). Selective deuteration methods have also been used, based on the isotopic exchange of protons by deuterons for exposed surface $\mathrm{OH}$ groups. Under vacuum, the resulting $v(\mathrm{OD})$ are spectrally shifted by a factor of $\sim 1.4$ to lower energy making them spectrally accessible and distinct from the bulk $\mathrm{OH}$ groups (which do not exchange with $\mathrm{D}_{2} \mathrm{O}$ or HOD). Selective deuteration methods have been used to characterize the surface hydroxyl groups of various clay minerals (de Donato et al., 2004; Ledoux \& White, 1964; Russell et al., 1970; Wada, 1967). The most definitive experiments, however, have been conducted on hydrous oxides (Parfitt et al., 1976; Rochester \& Topham, 1978; Russell et al., 1974; Sun \& Doner, 1996). In the well-characterized goethite system, for example, selective deuteration studies have shown that goethite is characterized by two main types of surface OD groups. For singly coordinated Fe-OH groups, the corresponding $v(\mathrm{OD})$ vibration occurs at a frequency of $2584 \mathrm{~cm}^{-1}$ in vacuo and for surface $\mathrm{OH}$ groups coordinated to two and three $\mathrm{Fe}$ atoms, the $v(\mathrm{OD})$ band occurs at a frequencies of $2700-2680 \mathrm{~cm}^{-1}$ in vacuo. This method can be used to assess the involvement of surface OH (OD) groups in ligandexchange reactions. For example, exposure of goethite to arsenate in aqueous suspension resulted in the complete loss of the singly coordinated OD groups at $2584 \mathrm{~cm}^{-1}$ resulting from the formation of an inner sphere surface complex through ligand exchange (Sun \& Doner, 1996). Similar results have been reported for goethite reacted with phosphate (Parfitt et al., 1976; Russell et al., 1974). The disadvantage of this approach is that the surface OD bands can only be observed in a high vacuum.

\section{CLAY -WATER AND \\ CLAY-ORGANIC INTERACTIONS $(0.3$ TO $\sim 10 \mathrm{~nm})$}

At the next larger scale shown in Fig. 1 we will consider clay-water and clay-organic interactions. The length scales associated with these interactions are not clearly defined but some reasonable boundaries can be established. For clay-water interactions, we assign a length scale which ranges from the diameter of the $\mathrm{H}_{2} \mathrm{O}$ molecule $(0.3 \mathrm{~nm})$ to the approximate upper limit of diffuselayer swelling of $10 \mathrm{~nm}$ (Lagaly, 2006; Norrish, 1954; Viani et al., 1983). The scale for clayorganic interactions considered here is based on the size of the organic solutes themselves. This extends from the size of small polar molecules $(\sim 0.4 \mathrm{~nm})$ to larger biomolecules, such as proteins, with sizes that approach $5 \mathrm{~nm}$. In terms of porosity, these length scales span from the 'microscopic' $(<2 \mathrm{~nm})$ to 'mesoscopic' ( 2 to $50 \mathrm{~nm}$ ) scales defined by the IUPAC and applied to clay minerals (Salles et al., 2009; Sing et al., 1985).

\section{Nanoconfined $\mathrm{H}_{2} \mathrm{O}$ in clay interlayers}

The molecular interactions of water with clay minerals are critically linked to essentially all chemical and physical aspects of clay science. Since the first reported IR study of water-smectite interactions in 1937 (Buswell et al., 1937), these interactions have been the subject of intense study using a broad spectrum of sophisticated experimental and computational approaches (Michot et al., 2002; Newman, 1987; Sposito \& Prost, 1982). Of interest here are the spatial scales at which clay-water interactions take place. The chemical mechanisms that contribute to clay-water interactions include $\mathrm{H}$ bonding, charge-dipole attraction, ligand-ligand repulsion, and van der Waals interactions. In addition, contributions can also occur through hydrolysis and redox reactions depending on the nature of the exchangeable cation. Although most of these forces operate at distances that do not exceed a few nanometres, well defined long-range 
ordering of clay particles does take place resulting from a 'long range attractive interparticle force' which is complex and thought to be electrostatic in nature (McBride, 1997; McBride \& Baveye, 2002). The underlying mechanisms that are responsible for diffuse-layer swelling are the continued subject of debate in the literature (Laird, 2006; McBride, 1997; McBride \& Baveye, 2002; Quirk, 2003).

In many respects, interfacial $\mathrm{H}_{2} \mathrm{O}$ molecules in clay interlayers and at the external periphery of clay particles are a fundamental 'part' of its structure. Removal of water, especially the water closely associated with the clay surface, can irreversibly change these minerals. This is the case for halloysite, for example, where removal of free and lumen water results in the irreversible collapse of the halloysite structure from a $d$ spacing of $1.0 \mathrm{~nm}$ to $0.7 \mathrm{~nm}$ (Joussein et al., 2005). Similarly, attempts to remove all of the water from smectites exchanged with some cations (e.g. $\mathrm{Li}^{+}, \mathrm{Na}^{+}, \mathrm{K}^{+}$, $\mathrm{Cs}^{+}$and $\mathrm{Mg}^{2+}$ ) through heating and evacuation result in their irreversible collapse resulting from the Hofmann-Klemen effect (Brindley \& Ertem, 1971; Farmer \& Mortland, 1966; Hofmann \& Klemen, 1950; Jaynes et al., 1992; McBride et al., 1975b).

We will focus our attention here on smectites as they are among the most interesting and important clay minerals when considering clay-water interactions (Schoonheydt \& Johnston, 2007). The physical picture that has emerged from a wide range of experimental and computational studies regarding smectite-water interactions is summarized as follows. The size and shape of smectite particles are very variable with shapes that vary from rhombic to subhedral lamella, hexagonal lamella to lathes and fibres (Guven, 1988; Ras et al., 2007b) and basal dimensions that vary from tens of $\mathrm{nm}$, as in the case of laponite, to a few micrometres for montmorillonite. In recent years, the development of Langmuir-Blodgett methods applied to clay science has provided new insights into the size, shape and particle-size distribution of smectites. Individual smectite particles consist of multiple layers of $1 \mathrm{~nm}$-thick 'fundamental particles' which are generally stacked on top of each other (Lagaly \& Malberg, 1990; Schramm \& Kwak, 1982) (Fig. 7). These particles have large aspect ratios and have a morphology similar to that of a torn sheet of paper (Lagaly, 2006; Ras et al., 2003). The number of particles stacked on top of each other varies as a function of the size and charge of the cation and on ionic strength. In the case of $\mathrm{Na}^{+}$and $\mathrm{Li}^{+}$at low ionic strength, the particles can be completely disarticulated into individual one nm-thick particles. For other cations, up to seven layers can be stacked on top of each other in structures referred to as tactoids as shown in Fig. 7 (Lagaly, 2006).

As shown in Fig. 8, isomorphous substitution in smectites can occur in the octahedral or tetrahedral sheet. Octahedral substitution (e.g. $\mathrm{Mg}^{2+}$ replacing $\mathrm{Al}^{3+}$ ) results in a charge deficit which is delocalized over $\sim 8$ surface oxygen atoms on each side of the fundamental particle, whereas substitution in the tetrahedral layer (e.g. $\mathrm{Al}^{3+}$ for $\mathrm{Si}^{4+}$ ) results in a more localized charge only on one side of the particle. Depending on the extent of substitution, the distance between the negatively charged sites ranges from 0.9 to $1.35 \mathrm{~nm}\left(1.2\right.$ to $\left.1.8 \mathrm{mmoles} / \mathrm{m}^{2}\right)$ (Środoń \& McCarty, 2008). However, because smectite layers are stacked on top of each other, the effective surface charge density is increased by a factor of two and the separation between negative charge sites is further reduced to $0.65-0.84 \mathrm{~nm}$ (Johnston \& Tombacz, 2002; Schoonheydt \& Johnston, 2007).

The interfacial chemistry of smectites is defined principally by interactions that occur between or within cation-water clusters in the interlayer region. Although the intrinsic negative surface charge of the clay can be balanced completely by cations forming inner sphere surface complexes, the strong hydration requirements of the most commonly occurring interlayer cations $\left(\mathrm{Ca}^{2+}\right.$, $\mathrm{Mg}^{2+}, \mathrm{K}^{+}$and $\mathrm{Na}^{+}$) maintains some metalcoordinated $\mathrm{H}_{2} \mathrm{O}$ between the clay layers. $\mathrm{H}_{2} \mathrm{O}$ molecules are attracted to metal cations through electrostatic interactions that maximize chargedipole attraction and minimize ligand-ligand repulsion (Feller et al., 1995; Glendening \& Feller, 1995, 1996). The hydrated cations are also attracted to the clay surface through electrostatic interactions (Rotenberg et al., 2009; Sutton \& Sposito, 2001; Teppen \& Miller, 2006). However, the binding energies of $\mathrm{H}_{2} \mathrm{O}$ molecules to the cation are large and result in the partial-to-full hydration of the exchangeable cations. Estimates of the binding energy of $\mathrm{H}_{2} \mathrm{O}$ molecules to metal ions from the vapour phase on a per- $\mathrm{H}_{2} \mathrm{O}$ molecule basis range from $<50 \mathrm{~kJ} \mathrm{~mol}^{-1}$ to $>320 \mathrm{~kJ} \mathrm{~mol}^{-1}$ depending on the nature of the cation and on the number of $\mathrm{H}_{2} \mathrm{O}$ molecules present (Rao et al., 2008). Thus, the interaction of the cation with the negatively charged 


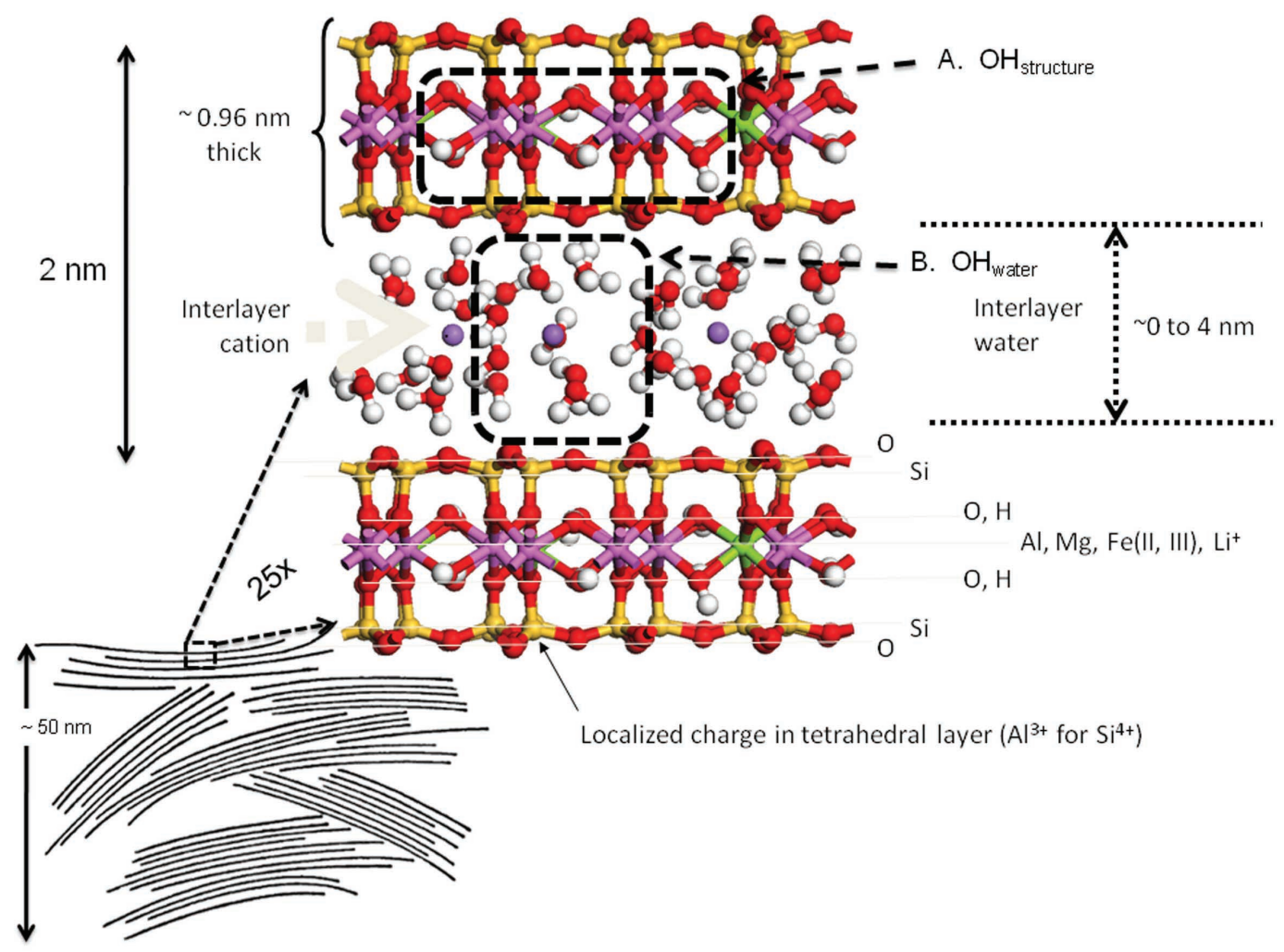

FIG. 7. Conceptual view of morphology of montmorillonite particles and an expanded view of two smectite layers.

siloxane surface is strongly modified by the presence of water.

These metal-coordinated $\mathrm{H}_{2} \mathrm{O}$ molecules are distinct from bulk water in several key aspects. First, they are polarized by the metal ion they are coordinated to through strong charge-dipole interactions. Figure 9 shows a top-down view of the siloxane surface showing the approximate spacing of hydrated monovalent metal ions corresponding to a medium charge density smectite (distance between cations of $0.75 \mathrm{~nm}$ ) for a one-layer hydrate $(d$ spacing of $1.25 \mathrm{~nm})$. The approximate molarity of cations in the interlayer region is $12 \mathrm{M}$, with $4 \mathrm{H}_{2} \mathrm{O}$ molecules coordinated to each cation. At small water contents, the cations direct the $\mathrm{H}_{2} \mathrm{O}$ molecules into coordination sites around the metal ions. In effect, this reduces H-bonding between $\mathrm{H}_{2} \mathrm{O}$ molecules. Unlike electrolyte solutions, the clay surface itself functions as a rigid, planar anion. As shown in the side view (left side of Fig. 9), these $\mathrm{H}_{2} \mathrm{O}$ molecules are 'nanoconfined'. For the one-layer hydrate, the gallery height of the interlayer is $0.3 \mathrm{~nm}$. Depending on the hydration requirements of the cation, the type and extent of isomorphous substitution, and the overall water content, the height of the gallery is very variable. Distances of up to three layers of $\mathrm{H}_{2} \mathrm{O}(0.9 \mathrm{~nm})$ are common. For monovalent cations at low ionic strength on low-to-medium charge smectites, these distances can increase to $4 \mathrm{~nm}$ and beyond. Interlayer distances of $10 \mathrm{~nm}$ have been reported (Norrish, 1954; Viani et al., 1983) and in some cases, complete separation or disarticulation of the layers is possible. Nanoconfined $\mathrm{H}_{2} \mathrm{O}$ is a feature common to a number of different types of clay minerals (Ockwig et al., 2009).

In this context, $\mathrm{H}_{2} \mathrm{O}$ clusters around exchangeable cations function as a hydrophilic probe of the clay surface. The planar $\mathrm{K}\left(\mathrm{H}_{2} \mathrm{O}\right)_{4}{ }^{+}$complex shown in Fig. 9 has an approximate footprint of $0.7 \times 0.7 \mathrm{~nm}$. The reactivity of the hydrated metal cluster is controlled, in part, by the ionic potential 


\section{Isomorphous substitution of $\mathrm{Mg} \rightarrow \mathrm{Al}$ in the octahedral layer (montmorillonite)}
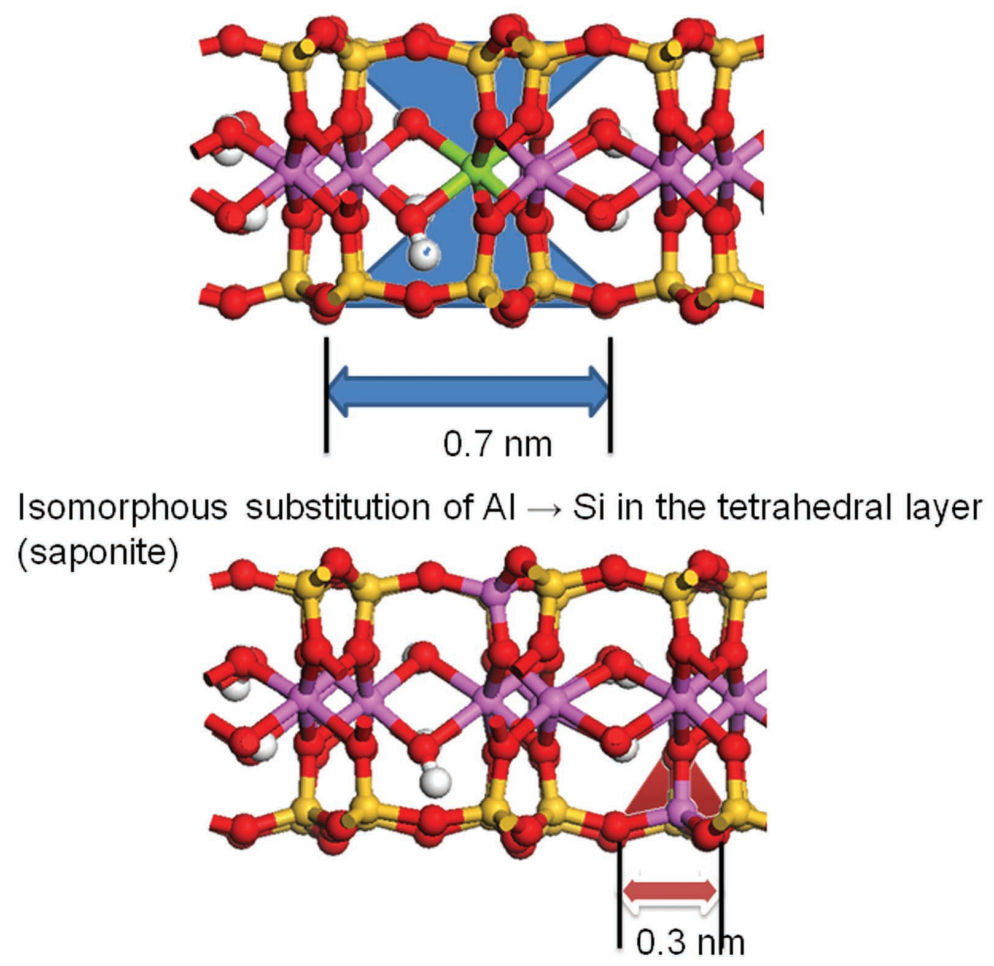

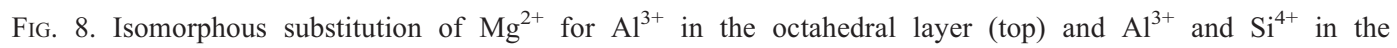
tetrahedral layer (bottom). Also shown are the approximate 'zones of influence' associated with this type of substitution.

of the exchangeable cation. For metal ions with large ionic potentials (e.g. $\mathrm{Fe}^{3+}$ and $\mathrm{Al}^{3+}$ ), these hydrated clusters are a source of acidity resulting from the hydrolysis of coordinated $\mathrm{H}_{2} \mathrm{O}$. From a spatial perspective, the size of the hydrophilic probe can be controlled by the charge and enthalpy of hydration of the exchangeable cation. It has been shown recently that in addition to influencing cation selectivity in the smectite interlayers, the energetics of cation hydration in the aqueous solution phase are major determinants of cation exchange behaviour (Salles et al., 2008; Teppen \& Miller, 2006). As will be discussed in the clay-organic section, the size of these hydrophilic domains is often inversely proportion to organic solute sorption.

One useful method to study clay-water interactions is to examine the properties of water itself. Vibrational spectroscopy has been successfully applied to study the interaction of water with clay surfaces (Johnston et al., 1992; Poinsignon et al., 1978; Russell \& Farmer, 1964; Sposito et al., 1983; $\mathrm{Xu}$ et al., 2000). The major vibrational bands of $\mathrm{H}_{2} \mathrm{O}$ occur in two regions corresponding to the $\mathrm{OH}$ stretching and $\mathrm{H}-\mathrm{O}-\mathrm{H}$ bending regions (Johnston \& Premachandra, 2001; Xu et al., 2000). In addition, the vibrational spectrum of $\mathrm{H}_{2} \mathrm{O}$ is also characterized by a broad band at $\sim 2127 \mathrm{~cm}^{-1}$ and lower frequency librational bands $<800 \mathrm{~cm}^{-1}$ (Carey \& Korenowski, 1998; Venyaminov \& Prenderast, 1997). In the $v(\mathrm{OH})$ region of $\mathrm{H}_{2} \mathrm{O}$, the $v(\mathrm{OH})$ bands of the clay interfere with those of $\mathrm{H}_{2} \mathrm{O}$. In addition, these bands are broad and complex due to the IR-activity of both the symmetric and asymmetric $v_{1}$ and $v_{3}$ modes. The $\mathrm{H}-\mathrm{O}-\mathrm{H}$ bending band of $\mathrm{H}_{2} \mathrm{O}$ ( $v_{2}$ mode), in contrast, occurs in a region relatively free from any clay absorption bands and the position of this band is sensitive to the extent of hydrogen bonding between $\mathrm{H}_{2} \mathrm{O}$ molecules 


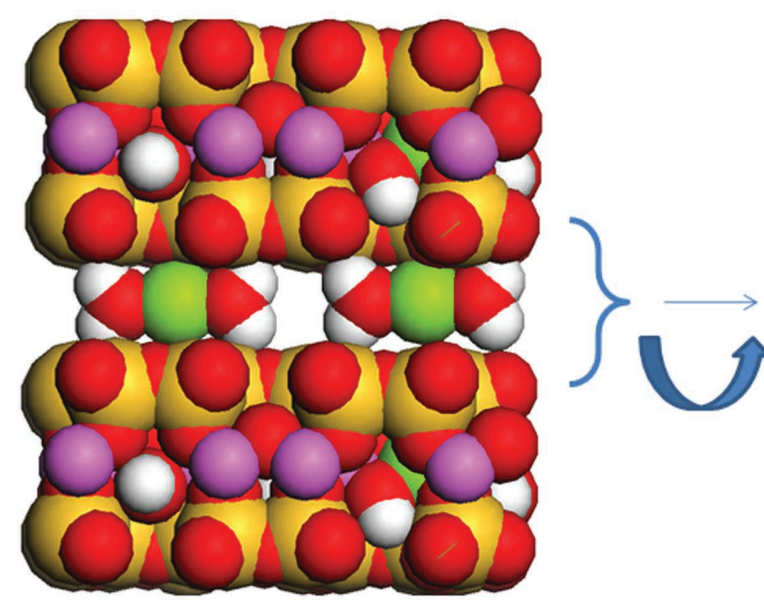

\section{View of water molecules surrounding interlayer cations}

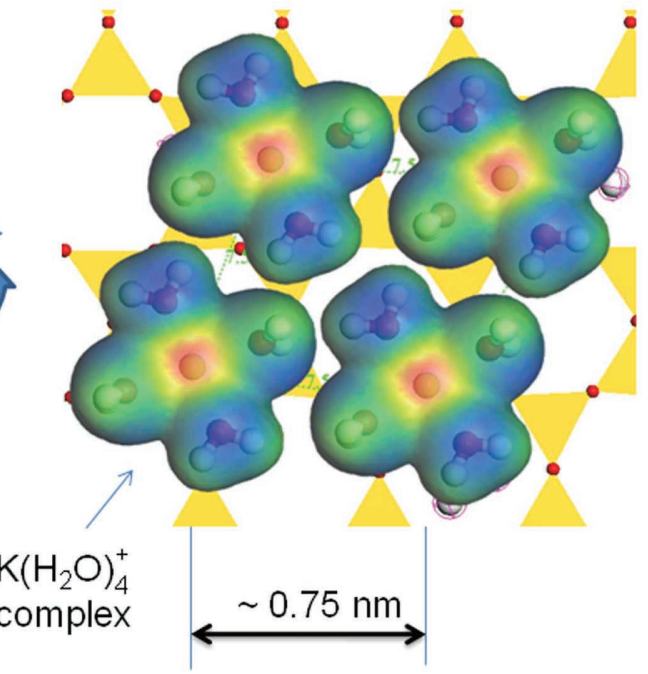

Fig. 9. Illustration of nanoconfined $\mathrm{H}_{2} \mathrm{O}$ corresponding to $4 \mathrm{H}_{2} \mathrm{O}$ molecules per interlayer $\mathrm{K}^{+}$. The right side illustrates a partial electrostatic potential map of hydrated K-smectite with a $d$ spacing of $1.25 \mathrm{~nm}$ and the left side illustrates the approximate distribution of hydrated cations in the interlayer. The red colour is associated with positive charge and the blue with negative.

(Pimentel \& McClellan, 1960, 1971). As hydrogen bonding is increased, the position of the $v(\mathrm{OH})$ bands of $\mathrm{H}_{2} \mathrm{O}$ shift to smaller energy and that of the $\mathrm{H}-\mathrm{O}-\mathrm{H}$ bending mode is increased (Falk, 1984; Fukuda \& Shinoda, 2008). At greater $\mathrm{H}_{2} \mathrm{O}$ contents of $>10 \mathrm{H}_{2} \mathrm{O} / \mathrm{Na}^{+}$cation, the position of the $\mathrm{H}-\mathrm{O}-\mathrm{H}$ bending band of $\mathrm{H}_{2} \mathrm{O}$ ( $v_{2}$ mode) occurs at $1635 \mathrm{~cm}^{-1}$ which is essentially that of bulk water (Venyaminov \& Prenderast, 1997). Upon lowering the $\mathrm{H}_{2} \mathrm{O}$ content to $<6 \mathrm{H}_{2} \mathrm{O} / \mathrm{Na}^{+}$cations, the position of this band shifts to smaller energy, indicating an overall decrease in H-bonding (Fig. 10, lower left). As the $\mathrm{H}_{2} \mathrm{O}$ molecules are clustered around the metal cations at small water contents, they are more restricted and less able to participate in intermolecular H-bonding with other $\mathrm{H}_{2} \mathrm{O}$ molecules (Poinsignon et al., 1978; Russell \& Farmer, 1964; Xu et al., 2000). Similarly, the molar absorptivity of the $\mathrm{H}-\mathrm{O}-\mathrm{H}$ bending band of sorbed $\mathrm{H}_{2} \mathrm{O}$ at large water contents $\left(12 \mathrm{H}_{2} \mathrm{O} / \mathrm{Na}^{+}\right)$is $20 \mathrm{~cm}^{2} / \mu \mathrm{mol}(\mathrm{Xu}$ et al., 2000) and equals that of bulk water (Venyaminov \& Prenderast, 1997). At smaller water contents, similar to the situation depicted in Fig. 10 (upper left), the $\mathrm{H}_{2} \mathrm{O}$ molecules are strongly polarized by the cation.
This is one example showing that the clay surface, and especially the proximity of the $\mathrm{H}_{2} \mathrm{O}$ molecules to the interlayer cations, perturbs the physiochemical properties of water. In addition, structural $\mathrm{OH}$ groups contained within the clay structure itself are influenced by changes in water content. Among the first to show this phenomenon were Sposito \& Prost (1982) who showed that the intensity of the structural $\mathrm{OH}$ bending bands increased significantly at larger water contents. Subsequent studies have quantified the change in molar absorptivity and the influence of water content on their band positions (Xu et al., 2000). In the case of montmorillonite, for example, there are three types of structural $\mathrm{OH}$ bending bands corresponding to $\mathrm{Al}-\mathrm{OH}-\mathrm{Al}, \mathrm{Al}-\mathrm{OH}-\mathrm{Fe}$, and $\mathrm{Al}-\mathrm{OH}-$ $\mathrm{Mg}$ groups which occur at 918,886 and $845 \mathrm{~cm}^{-1}$, respectively. The change in band position of these three bands is shown as a function of water content in Fig. 10 (right side). It is interesting to point out that the two structural $\mathrm{OH}$ bending bands whose band positions are most perturbed by lowering the water content, are associated with isomorphous substitution. Upon lowering the water content to $<6 \mathrm{H}_{2} \mathrm{O} / \mathrm{Na}^{+}$ions, a more direct cation-surface 

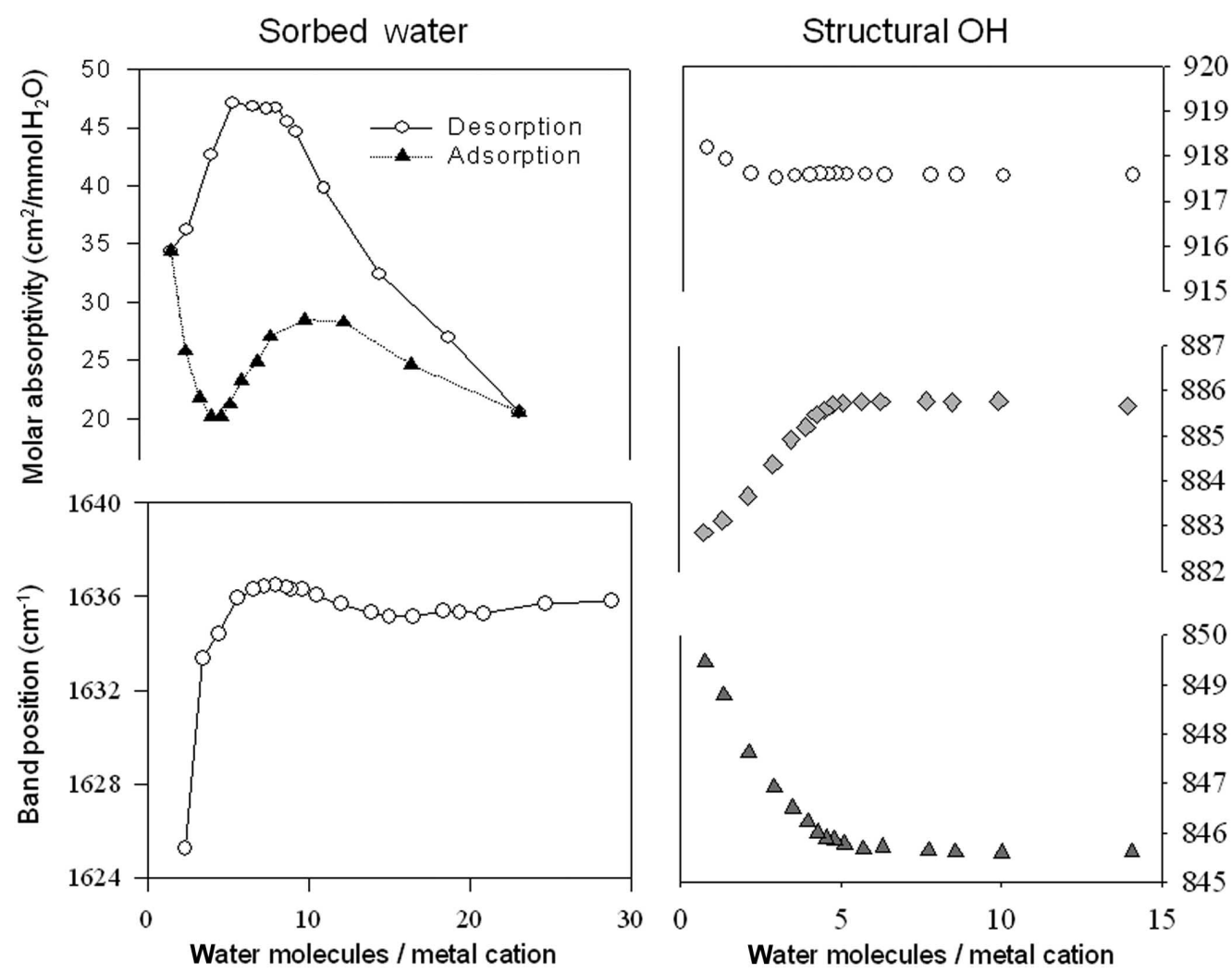

FIG. 10. Position of the H-O-H bending band of $\mathrm{H}_{2} \mathrm{O}$ sorbed on Na-SWy1 smectite as a function of water content expressed as the number of $\mathrm{H}_{2} \mathrm{O}$ molecules per exchangeable cation (lower left). Molar absorptivity of the H-O-H bending band of $\mathrm{H}_{2} \mathrm{O}$ observed during adsorption and desorption (upper left). Influence of water content on the position of the structural $\mathrm{OH}$ bending modes of $\mathrm{Na}-\mathrm{SWy} 1$ smectite are shown on the right-hand side. Adapted from Xu et al. (2000).

interaction can take place resulting in the observed shifts (Xu et al., 2000). The influence of water content on layer spacing and on the structural $\mathrm{OH}$ bending modes of the clay are also finding application in the interaction of biological molecules with clay surfaces (Haack et al., 2008).

These results from our laboratory are a few examples of how water and exchangeable cations interact with clay surfaces. An ever-increasing array of sophisticated experimental and computational techniques is being applied to clay-water systems. Examples include high-resolution X-ray reflectivity (Park et al., 2008; Schlegel et al., 2006), nonlinear optical methods (Ogawa \& Kuroda, 1995), vibrational spectroscopies (Johnston \& Premachandra, 2001; Johnston et al., 1992; Poinsignon et al., 1978; Ras et al., 2003; Rinnert et al., 2005; Russell \& Farmer, 1964; Xu et al., 2000), NMR spectroscopy
(Bowers et al., 2008; Delville, 1992) and electron spin resonance (ESR) spectroscopy (Clementz et al., 1973, 1974; McBride \& Mortland, 1974; McBride et al., 1975a,b,c). Studies that examine the dynamic properties of water in clay interlayers include neutron scattering (Bordallo et al., 2008; Cebula et al., 1981; Chang et al., 1997; Swenson et al., 2000), dielectric relaxation (Belarbi et al., 2007; Logsdon \& Laird, 2004; Salles et al., 2008) and NMR relaxation methods (Bowers et al., 2008). These experimental efforts are being supported and extended by a wide array of increasingly sophisticated computational methods.

In addition to the use of water as a molecular probe, the exchangeable cations themselves can be used to probe the clay surface. Some of the early ESR studies of Mortland, McBride and Clementz (Clementz et al., 1973, 1974; McBride \& Mortland, 
1974; McBride et al., 1975b) provided detailed molecular-level insight about the orientation of hydrated metal clusters in clay interlayers as a function of clay type, metal ion and water content. ESR spectra obtained from oriented clay films at controlled relative humidity confirmed the orientation of the hydrated $\mathrm{Cu}\left(\mathrm{H}_{2} \mathrm{O}\right)_{4}^{2+}$ and $\mathrm{Cu}\left(\mathrm{H}_{2} \mathrm{O}\right)_{6}^{2+}$ complexes in the smectite interlayer which is shown in Fig. 11 (Clementz et al., 1973). At present, nuclear magnetic resonance (NMR) methods are commonly used to study the molecular environment of NMR-active cations and a partial listing of NMR nuclei which have been successfully used in clay studies is shown in Fig. 12. In recent years, cationspecific high-resolution X-ray reflectivity methods are being applied to clay-related systems, such as the external surface of muscovite (Park et al., 2008; Schlegel et al., 2006).

Clay-organic interactions are largely dependent on water-cation interactions at the clay interface. From the perspective of surface chemistry, the extent to which the clay surface is rendered hydrophilic depends on the type of cation, the surface charge density of the clay and the predominant location of isomorphous substitution in the clay lattice. Smectite surfaces generally show selectivity for organic cations and protonated organic bases (Johnston, 1996; Mortland, 1970; Theng, 1974). In broad terms, sorption of all other organic solutes can occur to some extent if the clay surface is not strongly hydrophilic. As will be developed below, sorption of semi-to-nonpolar organic solutes can occur in smectite interlayers for low charge, tetrahedrally substituted clays exchanged with less hydrated monovalent cations (e.g. $\mathrm{K}^{+}$or $\mathrm{Cs}^{+}$). For strongly hydrated cations, the 'hydration spheres' of these cations are larger than the average separation between cations (0.65 to $0.85 \mathrm{~nm}$, see Fig. 9) and the organic solutes cannot effectively compete with $\mathrm{H}_{2} \mathrm{O}$ for interlayer sorption sites.

\section{CLAY-ORGANIC INTERACTIONS}

Similar to the use of hydrated metal clusters as hydrophilic probes of clay minerals, the reactive sites, topography and hydrophilic-hydrophobic character of clay minerals can also be accessed through studies of organic solutes and polymers. The use of clay-organic materials in a wide range of disciplines including nanoscience and nanotechnology is rapidly expanding as attested by the number of publications and patents being issued each year (Dubois, 2007). A comprehensive review of clay-organic interactions is beyond the scope of this review and has been the subject of review (Johnston, 1996; Lagaly et al., 2006; Ras et al., 2007b). Unlike prior reviews of clay organic interactions that have focused mainly on classes of organic solutes (e.g. organic cations, bases, etc. - see Johnston, 1996; McBride, 1994; Mortland, 1970; Zielke et al., 1989), emphasis here is placed on the use of organic solutes as molecular probes of clay surfaces and is organized around the size, shape, polarity and reactivity of the organic solutes. These extend from small polar molecules used to intercalate kaolin subgroup minerals to larger more complex organic solutes.
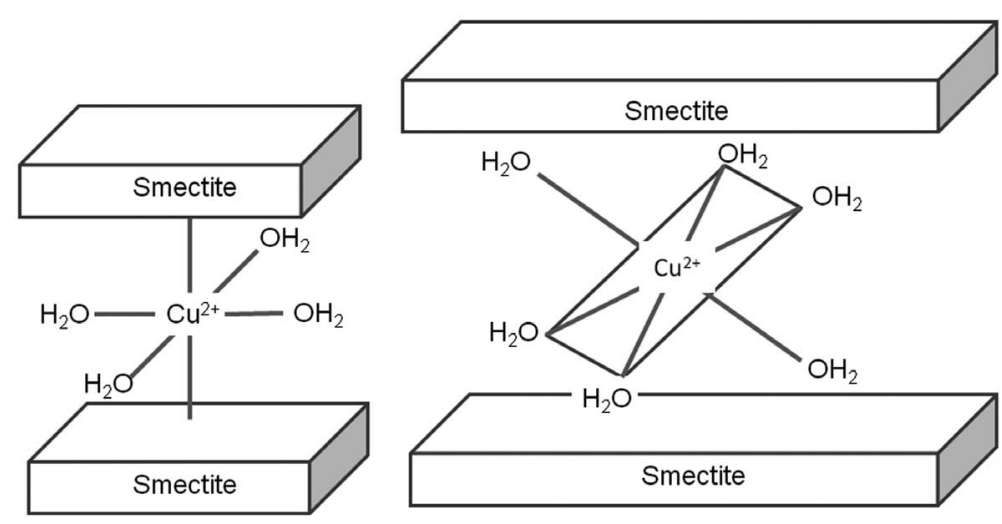

FIG. 11. Orientation of hydrated $\mathrm{Cu}\left(\mathrm{H}_{2} \mathrm{O}\right)_{4}^{2+}$ and $\mathrm{Cu}\left(\mathrm{H}_{2} \mathrm{O}\right)_{6}^{2+}$ complexes determined from polarized ESR spectra obtained from oriented clay films at controlled relative humidity (Clementz et al., 1973). 


\section{Exchangeable cations:}

${ }^{6} \mathrm{Li},{ }^{23} \mathrm{Na},{ }^{39} \mathrm{~K},{ }^{113} \mathrm{Cd},{ }^{133} \mathrm{Cs}$

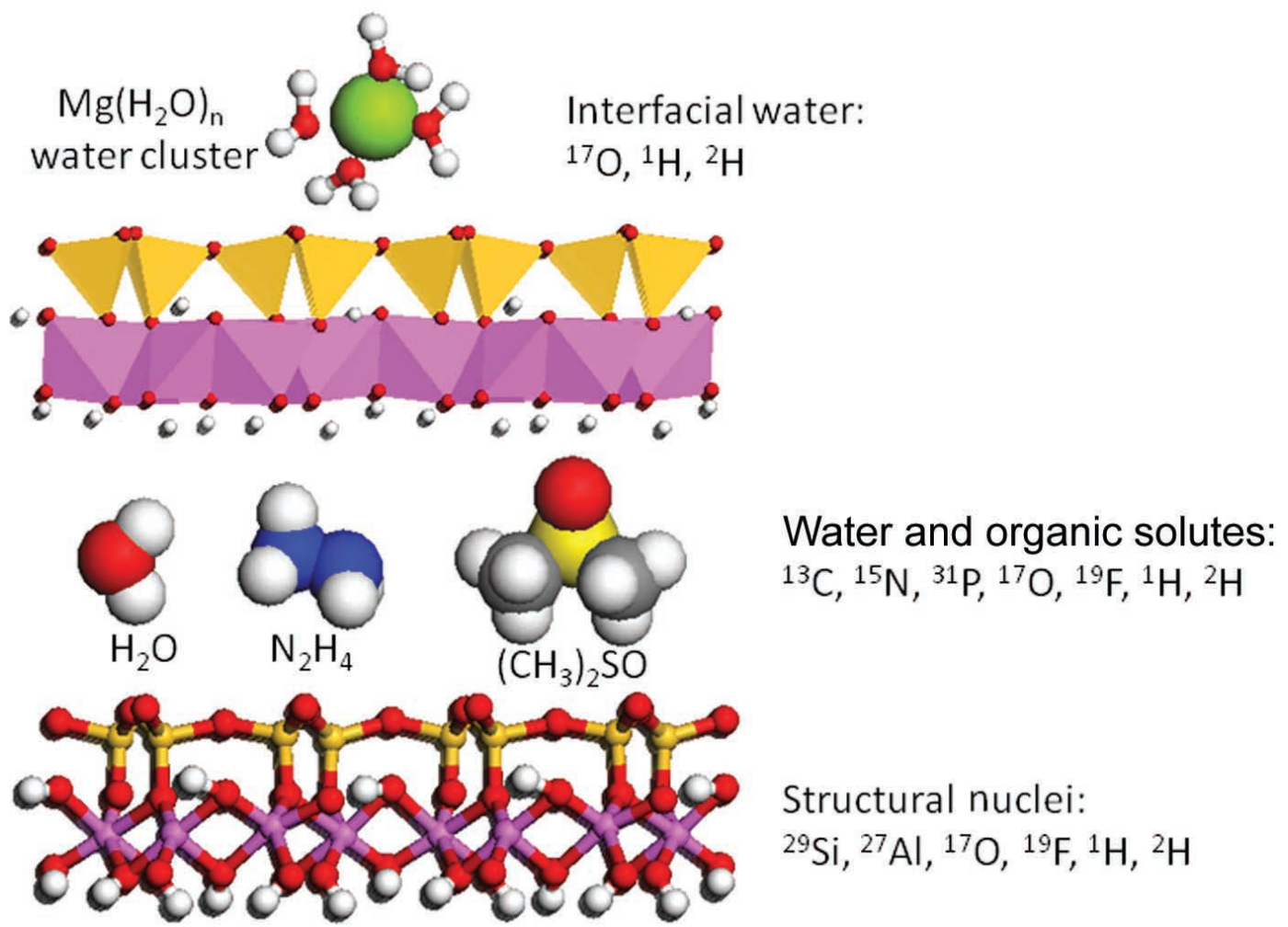

FIG. 12. A conceptual picture of the NMR-active nuclei used to study clay minerals, clay-water, cation exchange, and clay-organic interactions.

Small polar molecules: kaolinite intercalates

As discuss earlier, the interlayer H-bonds in kaolin subgroup minerals are responsible for their geochemical stability and predominance in very weathered soils. These bonds are shown in the [010] projections of kaolinite in Fig. 3. From an energetic standpoint, these layers are difficult to 'pry apart' and, as a result, intercalation is limited to a handful of small molecules shown in Fig. 13. These molecules are small enough to be intercalated between the layers and have polar characteristics such that favourable surface interactions can occur with both types of surfaces found in the interlayer region. In nature, halloysite (middle of Fig. 14) is the only naturally occurring intercalation complex of kaolinite and its occurrence, morphology and characterization have recently been reviewed
(Joussein et al., 2005). The structure of halloysite consists of one layer of $\mathrm{H}_{2} \mathrm{O}$ sandwiched between each fundamental layer of kaolinite $\left(4 \mathrm{H}_{2} \mathrm{O}\right.$ molecules per unit cell). Thus, all of the interlayer innersurface $\mathrm{OH} \cdots \mathrm{O}$ pairings are replaced by innersurface $\mathrm{OH}-\mathrm{H}_{2} \mathrm{O}$ and $\mathrm{H}_{2} \mathrm{O}$-siloxane interactions.

As noted earlier, the $v(\mathrm{OH})$ vibrations of the structural $\mathrm{OH}$ groups of kaolin subgroup minerals are very sensitive to changes in their local environment resulting from layer stacking disorder, as well as changes in temperature and pressure. Similarly, the $v(\mathrm{OH})$ bands of kaolin subgroup minerals are strongly perturbed upon intercalation as the existing $\mathrm{O}-\mathrm{H} \cdots \mathrm{O}$ pairings of kaolinite are replaced by a new set of $\mathrm{O}-\mathrm{H} \cdots \mathrm{X}$ pairings. Although other types of chemical bonding are involved in these complexes, all of the intercalates share a common feature, i.e. formation of 'new' $\mathrm{H}$ bonds with $\mathrm{Al}(\mathrm{OH})_{x}$ surface 


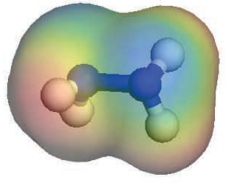

Hydrazine

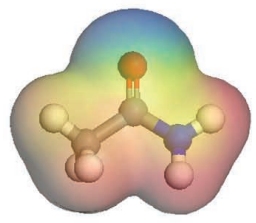

Acetamide

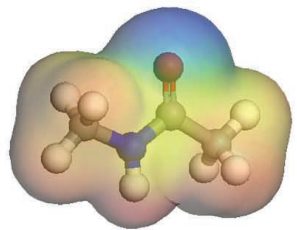

$\mathrm{N}$ methyl

acetamide

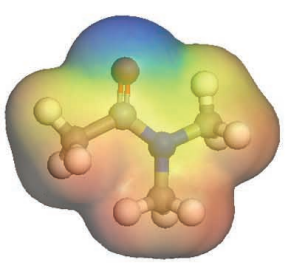

Dimethyl acetamide

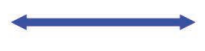

$0.5 \mathrm{~nm}$

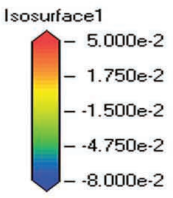

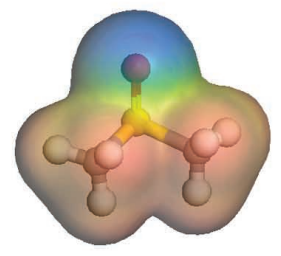
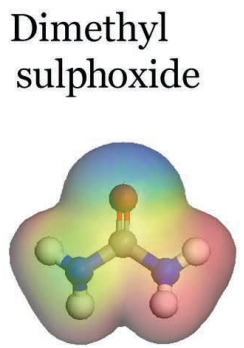

Urea

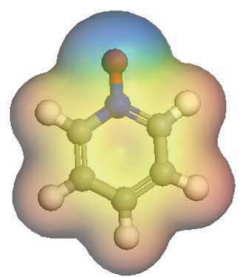

Pyridine $\mathrm{N}$ oxide

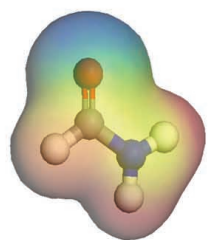

Formamide

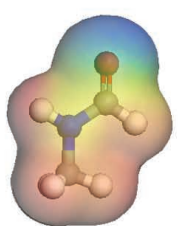

N methyl formamide

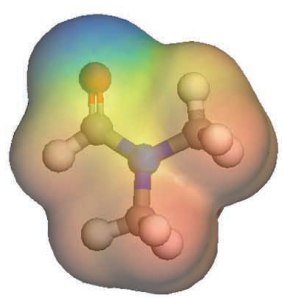

Dimethyl formamide

FIG. 13. Structures and electrostatic potential maps of 'primary intercalates'

kaolinite in the interlayer. These compounds include dimethyl sulphoxide, formamides, hydrazine, and ureas (Fig. 13). As such, these molecules function as polar molecular probes of the kaolinite interlayer. The crystal structure of the kaolinite-DMSO complex with a $d$ spacing of $1.13 \mathrm{~nm}$ and that of the kaolinitehydrazine complex with a $d$ spacing of $0.95 \mathrm{~nm}$ are shown in Fig. 15 (Johnston et al., 2000; Thompson $\&$ Cuff, 1985). For the kaolinite-DMSO complex, the oxygen atom of the sulphonyl group interacts with the inner-surface $\mathrm{OH}$ groups. These molecules have the ability to interact favourably with both the siloxane and hydroxyl surface and to overcome the existing interlayer attractive forces. As molecular probes, the effective length scale here is the molecular dimension of the intercalated species and is limited to the size of the intercalates which is $<0.5$ $\mathrm{nm}$. Although direct intercalation is limited to the 
Kaolinite

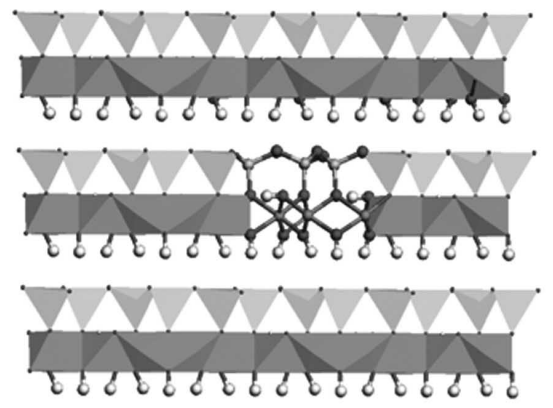

Halloysite
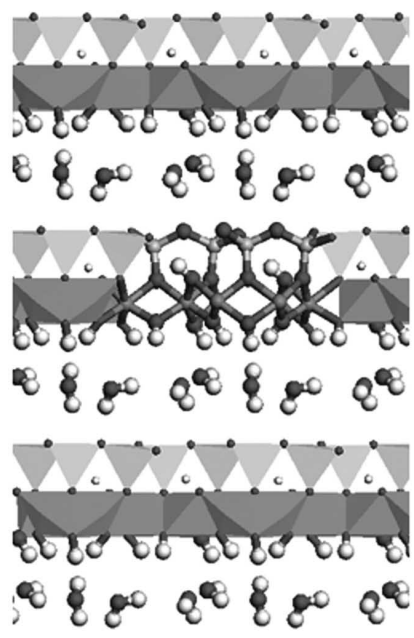

Structural $\mathrm{OH}$ groups and $\mathrm{OH}$ from water

\section{Kaolinite-hydrazine Intercalation complex}
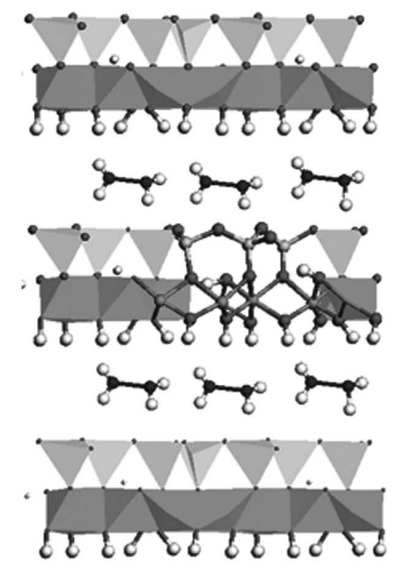

FIG. 14. [010] projection of kaolinite, halloysite and of the 0.95 kaolinite-hydrazine intercalation complex.

small group of intercalates shown in Fig. 13, larger molecules can be introduced into the interlayer by first expanding the interlayer using one of the 'primary intercalates' shown in Fig. 13. These materials, however, can be used as intermediates and subsequent intercalation is possible to $d$ spacings of $1.7 \mathrm{~nm}$ and beyond (Elbokl \& Detellier, 2008; Letaief et al., 2008).

Vibrational and NMR spectroscopy combined with X-ray diffraction and thermal analysis have been the traditional methods to study intercalation processes (Johnston et al., 1984; Ledoux \& White, 1966; Olejnik et al., 1968, 1971; Thompson, 1985; Thompson \& Cuff, 1985) and remain among the most useful techniques. In addition to the perturbation of the kaolinite $v(\mathrm{OH})$ modes, these intercalates have functional groups that are perturbed by the clay surface. Examples include the sulphonyl stretching vibration $(v(\mathrm{~S}=\mathrm{O}))$ of $\mathrm{DMSO}$ or the vibrational modes associated with the $-\mathrm{NH}_{2}$ group of hydrazine. Many different permutations of NMR spectroscopy have been used successfully to characterize these intercalation and functional materials. NMR spectroscopy provides an opportunity to examine both structural nuclei $\left({ }^{29} \mathrm{Si},{ }^{27} \mathrm{Al}\right.$, ${ }^{17} \mathrm{O},{ }^{1} \mathrm{H}$ and ${ }^{2} \mathrm{H}$ ) as well as nuclei of the intercalated species (e.g. ${ }^{13} \mathrm{C},{ }^{31} \mathrm{P},{ }^{1,2} \mathrm{H}$ ). In addition, the time scale associated with NMR spectroscopy is somewhat longer than that of vibrational spectroscopy and dephasing techniques can be used to study molecular motion in clay interlayers (Brandt et al., 2003; Elbokl \& Detellier, 2008; Lipsicas et al., 1986; Tonle et al., 2007). An illustration of some of the NMR-active nuclei used to study kaolinite intercalation complexes, and related clay studies, is given in Fig. 12.

Recently, attention has focused on treatment of kaolinite through surface modification. These methods include chemical grafting of organic molecules onto the internal surfaces of kaolinite, or replacement of smaller intercalated molecules with larger molecules. One interesting example was the insertion of p-nitroaniline into kaolinite interlayers (Kuroda et al., 1999). Because of the dissimilar surfaces present in expanded kaolinite, the intercalated p-nitroaniline adopted an acentric 


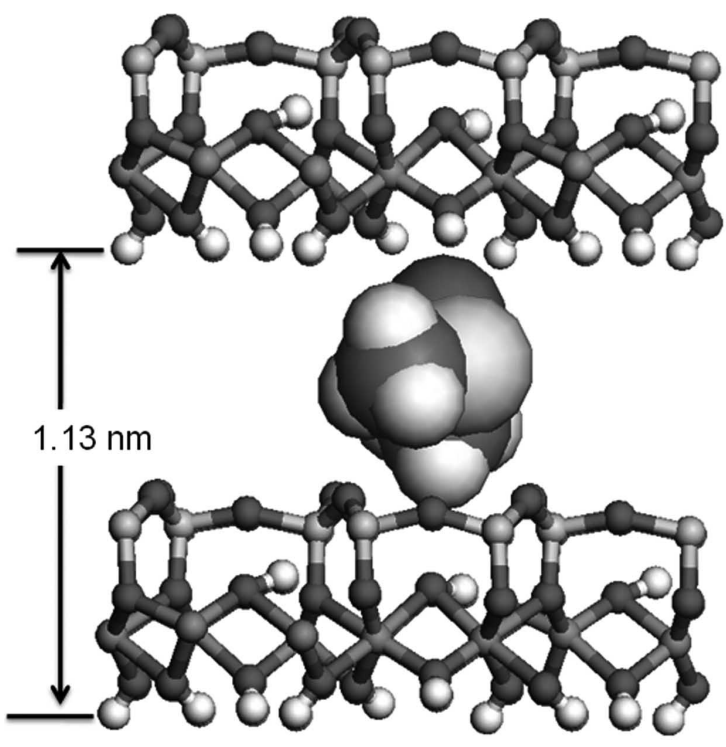

Kaolinite-DMSO

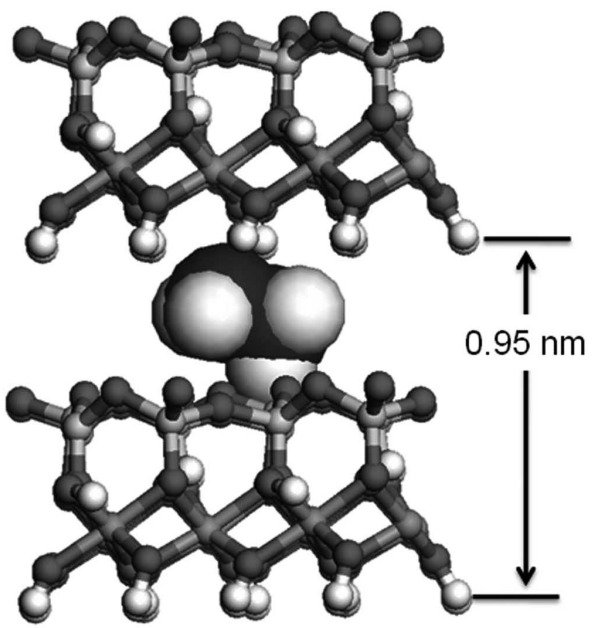

Kaolinite-hydrazine

FIG. 15. [010] projections of the kaolinite-DMSO and kaolinite-hydrazine complex.

arrangement where the $-\mathrm{NO}_{2}$ groups interacted with the inner-surface $\mathrm{OH}$ groups and the $-\mathrm{NH}_{2}$ group could favourably interact with the siloxane surface and the resulting kaolinite-p-nitroaniline intercalation complex was optically active. Current efforts are focused on surface modification through grafting reactions, such as organosilyl and ethoxy groups on the interlamellar surfaces of kaolinite (Tonle et al., 2007).

Synthesis and characterization of functional materials based on intercalation of organic guest molecules into layered inorganic materials is an area of considerable interest at present in the search for novel materials for nanocomposites, sensing, catalysis, improved thermophysical properties, adsorption and related applications. In the realm of clay-organic hybrid materials, kaolin group minerals have some interesting applications based on the fact that unlike $2: 1$ phyllosilicates, kaolin subgroup minerals have a permanent dipole moment due to their structural asymmetry. Unlike 2:1 clay minerals, guest molecules intercalated into kaolin subgroup minerals interact with two distinct types of surfaces (Johnston \& Tombacz, 2002; Schoonheydt \& Johnston, 2007).

One noteworthy aspect of kaolinite intercalates is that, in some cases, the intercalated species can partially 'key' into the siloxane ditrigonal cavity.
This has been observed for kaolinite where partially collapsed halloysite-like structures with $d$ spacings 0.84 and 0.92 have been prepared (Costanzo \& Giese, 1985, 1990; Costanzo et al., 1982). Similarly, the $-\mathrm{NH}_{2}$ group of hydrazine has also been observed to partially key into the siloxane ditrigonal surface where the reversible partial collapse of the structure has been observed (Cruz \& Franco, 2000; Johnston et al., 1987, 2000; Johnston \& Stone, 1990). Similar phenomena have also been observed in 2:1 phyllosilicates where interlayers cations can partially penetrate into the clay surface (Fernandez et al., 1970). In all of these examples, evidence for keying into the clay surface is derived from the partial collapse of the structures observed through XRD and infrared spectroscopy where the inner $\mathrm{OH}$, the structural $\mathrm{OH}$ group located between the sheets, is perturbed in the collapsed form. The point to be emphasized here is that, in some cases, the interaction of the organic solute with the clay surface can be observed through structural components of the clay itself.

\section{Neutral organic contaminants (NOCs): nitroaromatic smectite interactions}

The fate of neutral organic contaminants (NOCs) in soil and subsurface environments has been studied 


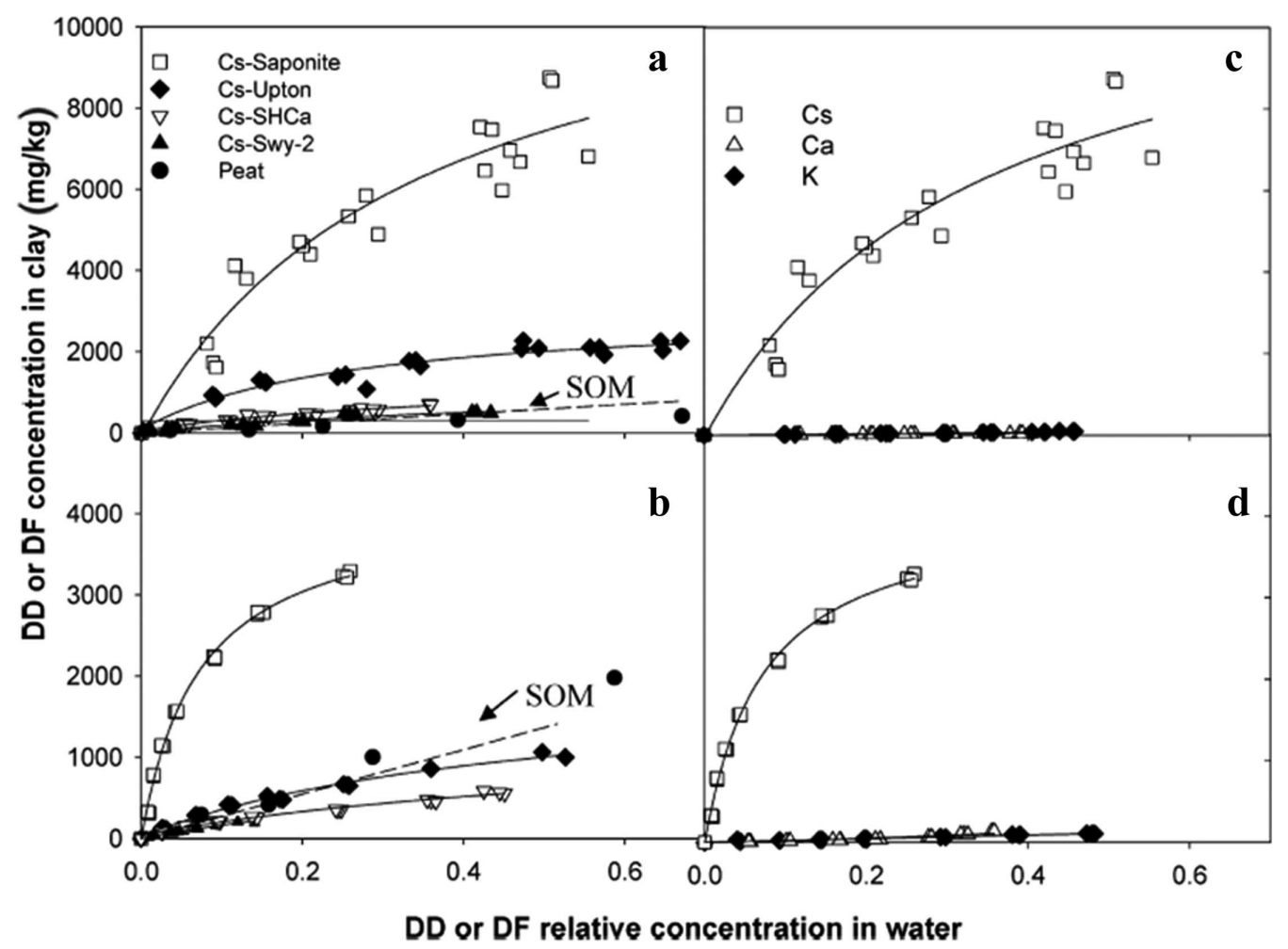

FIG. 16. Adsorption isotherms representing (A) dibenzodioxin (DD) or (B) dibenzofuran (DF) uptake from water by Cs-saturated smectites (saponite, SapCa-2; montmorillonite, Upton and SWy-2; hectorite, SHCa), and Pahokee peat (Liu et al., 2009, used with permission). SOM = soil organic matter.

intensively for the past 40 years. Although NOCs include a wide range of compounds, for the sake of illustration we will focus our attention on nitroaromatic compounds (NACs). Although beyond the scope of this review, the interaction of triazines (Barriuso et al., 1994; Chappell et al., 2005; Laird et al., 1992) and carbamate compounds (De Oliveira et al., 2005; Haack et al., 2008) appear to follow similar trends and, in this context, provide functional-chemistry specific probes of clay surfaces. Haderlein and co-workers were among the first to show that certain NACs exhibited a great affinity for smectites (Haderlein \& Schwarzenbach, 1993; Haderlein et al., 1996; Weissmahr et al., 1997) with wide variation in sorption depending on subtle difference between the NACs. Subsequently, molecular details about their interaction with smectites was provided through coupled sorption-spectroscopic-structural-molecular modelling studies (Johnston et al., 2004). Within this context, the following structural features are relevant. When the
$-\mathrm{NO}_{2}$ groups do not occupy adjacent ring positions and bulky substituents are not present, NACs adopt a planar configuration. When two and especially three such coplanar $-\mathrm{NO}_{2}$ groups are present on a single ring (i.e. 1-3 or 1-4 dinitrobenzene (DNB) and 1,3,5trinitrobenzene (TNB)), sorption on smectite is significantly enhanced showing the preference of smectite surfaces for planar structures (Boyd et al., 2001; Weissmahr et al., 1997). For planar molecules, or molecules containing planar substituents, polarized FTIR methods can be used to determine the molecular orientation of the sorbed species (Ahn \& Franses, 1992; Ras et al., 2007a). In the case of dinitro-o-cresol (DNOC) sorbed on montmorillonite, polarized FTIR and X-ray diffraction (XRD) data revealed that the molecular orientation of DNOC was parallel to the clay surface (Sheng et al., 2002).

In addition to providing information about the molecular orientation of sorbed nitroaromatic compounds on clay minerals, the vibrational modes associated with the $-\mathrm{NO}_{2}$ groups are sensitive to 
inter- and intramolecular interactions and have been used as indicators of change in the local environment of the sorbed nitroaromatic compound. In particular, the positions and intensities of the symmetric and asymmetric nitrogen oxygen stretching bands (i.e. $v_{\text {asym }}(\mathrm{NO})$ and $v_{\text {sym }}(\mathrm{NO})$ ) are sensitive to molecular interactions in the local environment of the $-\mathrm{NO}_{2}$ groups. Analysis of these bands for a number of NACs sorbed on different types of smectites (e.g. high-charge, lowcharge, reduced-charge clays) exchanged with alkali and alkaline earth metal ions revealed that the $-\mathrm{NO}_{2}$ groups interacted favourably with the exchangeable cations in the interlayer (Boyd et al., 2001; Johnston et al., 2001, 2002a; Sheng et al., 2002). These interactions have been the subject of a recent review and are summarized briefly here. With respect to clay properties, greatest sorption occurs for 'lowcharge' smectites that are exchanged with weakly hydrated exchangeable cations (e.g. $\mathrm{K}^{+}$and $\mathrm{Cs}^{+}$). NAC sorption determinants are the number of $-\mathrm{NO}_{2}$ groups, planarity of the structure and presence of other substituents on the ring. The greatest interaction between $\mathrm{NAC}-\mathrm{NO}_{2}$ groups and the exchangeable cations was observed for weakly hydrated cations. As noted earlier, the enthalpy of hydration of the exchangeable cation determines the overall size of the hydrated metal cluster in the clay interlayer. Favourable stabilization energy between the NAC and exchangeable cation can occur provided that the $-\mathrm{NO}_{2}$ groups can gain molecular access to the cation. Increased stabilization is also provided by the presence of additional $-\mathrm{NO}_{2}$ groups. The charge density of the clay also plays a significant role. If the hydrated metal clusters in the clay interlayer are too close, such that no sorptive domains exist for the NAC, then sorption will be diminished. The region between the isomorphous substitution sites on the clay surface is termed the neutral siloxane surface. There has been some debate in the literature about the role of this surface in providing additional stabilization energy for NACs with electron density from the siloxane oxygen atoms being donated to the delocalized p-electrons of the aromatic ring (Boyd et al., 2001; Weissmahr et al., 1998; Zhu et al., 2004).

\section{Heterocyclic organic compounds: dibenzo-p- dioxin and dibenzofuran}

Among the most toxic and carcinogenic compounds known to humans are the tricyclic aromatic ether compounds known as dioxins. The chlorinated dioxins, toxic end-members of the group known as persistent organic pollutants, can activate biological receptors at exceptionally small aqueous solution concentrations. As a result, regulatory limits for dioxins are orders of magnitude lower than any other non-radioactive contaminant and this has prompted considerable interest in its environmental chemistry. Through an unusual course of events, starting with an occurrence of elevated levels of dioxins in chickens (Ferrario \& Byrne, 2000; Hayward \& Bolger, 2005; Hayward et al., 1999), an unlikely connection between these nonpolar organic solutes and clay minerals was established. As discussed earlier, most clay minerals in general, and smectites in particular, are strongly hydrophilic. At the same time, however, recent studies have established that certain smectites have a great affinity for dibenzop-dioxin (DD) and dibenzofuran (DF) in aqueous sorption studies (Liu et al., 2009; Rana et al., 2009). As a class of molecules, dioxins provide an interesting suite of hydrophobic probe molecules.

Dioxins are hydrophobic, planar compounds that do not have polar functional groups. In fact, their adverse biological activity is associated with this structural feature. Activation of the aryl hydrocarbon receptor occurs through a binding site that is a hydrophobic 'slot' formed between two proteins that measures $1.4 \mathrm{~nm} \times 1.2 \mathrm{~nm} \times 0.5 \mathrm{~nm}$ (Denison \& Nagy, 2003). As shown in Fig. 16, sorption of DD on smectite from aqueous suspension is largely dependent on the nature of the interlayer cation and clay type (Liu et al., 2009; Rana et al., 2009). Sorption of DD from aqueous suspension favours low-charge, tetrahedrally substituted clays exchanged with weakly hydrated cations. Sorption on Cs-saponite is $\sim 10,000 \mathrm{mg}$ of $\mathrm{DD} / \mathrm{kg}_{\text {saponite }}$ or $1 \%$ by mass. What can we learn about the clay surface from the interaction of DD with surface of Cs-saponite? First, the role of the exchangeable cation plays a critical role. Although NAC sorption was enhanced by weakly exchanged cations, in the case DD or DF, sorption is $>2$ or 3 orders of magnitude greater for Cs-exchanged clays. Second, sorption is much greater on tetrahedrally substituted clays (e.g. saponite) compared to smectites with octahedral substitution. When isomorphous substitution occurs in the octahedral sheet, the charge is delocalized over $>6$ surface oxygen atoms and this occurs on both sides of the fundamental particles (now for a total of 12 oxygen atoms). In contrast, 

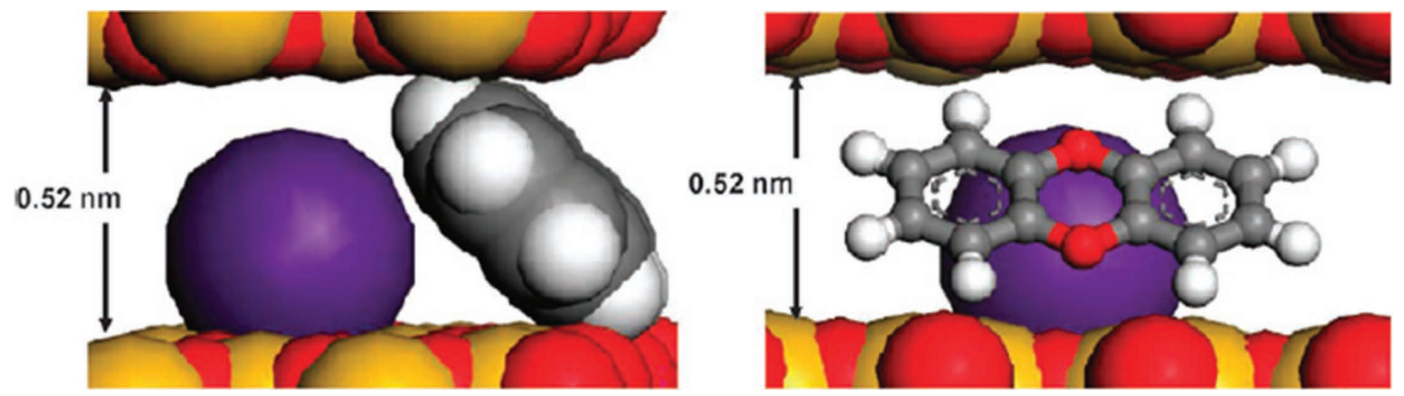

FIG. 17. Proposed molecular model of DD-smectite complex showing the arrangement of DD in the interlayer space of the smectite clay.

the charge is highly localized in tetrahedrally substituted clays and this only occurs on one side (see Fig. 8). The net result is that significantly larger 'patches' of the neutral siloxane surface that are not influenced by isomorphous substitution occur in saponite and this, in turn, is responsible for the greater sorption of DD on saponite.

Similar to nitroaromatic compounds, planar molecules like DD have in-plane and out-of-plane vibrational modes. Based upon polarized FTIR measurements (Rana et al., 2009) and XRD analysis (Liu et al., 2009), the orientation of DD in the interlayer was tilted at an angle of $\sim 30^{\circ}$ with respect to the clay surface. The molecular symmetry of DD is centrosymmetric; as a result, certain vibrational modes are observed only in the IR and others only in the Raman mode. When sorbed to Cs-saponite, however, the selection rules of sorbed DD are relaxed, showing activity in both Raman and IR, indicating that the molecular symmetry of DD was 'broken'. When combined with the tilted orientation, the molecular configuration of the DD in the clay interlayer was consistent with one of the etheroxygen atoms resting on a $\mathrm{Cs}^{+}$cation in the interlayer as shown in Fig. 17. In these experiments, DD and DP provide unlikely but useful probes of the smectite surface, showing a great degree of specificity for non-hydrated sorption sites on the neutral siloxane surface.

\section{Interaction of biological molecules with clay minerals: clay-protein interactions}

Interest in the interaction of biomolecules with minerals has significantly increased in recent years in a wide range of disciplines that span from nanobiotechnology to nanoelectronics and nanome- dicine (Bromley et al., 2007; Darder et al., 2007; Patil \& Mann, 2008). For a number of years, immobilization of enzymes (bio-immobilization) on clay minerals, wherein the stability and activity or the enzyme is preserved, has been the subject of attention (Albert \& Harter, 1973; Chen et al., 2008; Garwood et al., 1983; Harter \& Stotzky, 1971; Mortland \& Lawless, 1983). Of particular relevance to biomolecules-clay interactions is the dual hydrophobic-hydrophilic character of clay minerals described above and in greater detail recently by Schoonheydt \& Johnston (2007). The interaction of proteins with clay minerals has been studied for many years within the realm of soil chemistry (Albert \& Harter, 1973; Boyd \& Mortland, 1985; De Cristofaro \& Violante, 2001; Ensminger \& Gieseking, 1939, 1941, 1942; Garwood et al., 1983; Harter, 1975; Harter \& Stotzky, 1971; Mclaren \& Peterson, 1961; Mclaren et al., 1958; Naidja et al., 1995). Many different types of proteins and enzymes are released into the soil and are retained on clay mineral surfaces (Gianfreda et al., 2002). Proteins and related biopolymers bound to clay minerals serve to regulate biological activity in soils and maintain certain aspects of microbial nutrition. The interaction of enzymes with clay surfaces modifies their catalytic activity and intercalated proteins are somewhat protected in the interlamellar region. At the same time, however, their catalytic ability is compromised because substrates must be able to enter into the interlamellar region and to follow a tortuous diffusion path in order to reach the active site.

Proteins represent a large and complex suite of structural probes to examine clay minerals. The size, shape, charge, flexibility, reactivity and hydrophilic/ hydrophobic nature of proteins are diverse. To 
promote this concept, we will focus our attention on the interaction of lysozyme with smectites. Lysozyme has long been viewed as a model protein to study clay-protein interactions because of its great affinity for smectites and ability to intercalate into clay interlayers (Albert \& Harter, 1973; Harter, 1975; Harter \& Stotzky, 1971; Mclaren \& Peterson, 1961; Mclaren et al., 1958; Violante et al., 1995). In fact, over 50 years ago, McLaren and co-workers established that interlayer expansion of montmorillonite could be used as a calliper for the size of proteins (Mclaren \& Peterson, 1961; Mclaren et al., 1958). As a probe molecule, lysozyme is a hard, compact, globular protein with an isoelectric point (IEP) of 11.1 and a mass of $14.3 \mathrm{kDa}$. Sorption of lysozyme occurs in excess of the cation exchange capacity and results in interlayer expansion to $d$-spacing values of $>4 \mathrm{~nm}$ consistent with a monolayer based on the dimensions of the lysozyme molecule of $4.5 \times 3.0 \times 3.0 \mathrm{~nm}$ (Walsh et al., 1998; Wang et al., 2007). The mechanism of interaction is through cation exchange with $\sim 10 \mathrm{Na}^{+}$ ions released for every molecule of lysozyme sorbed (Albert \& Harter, 1973). The IEP of lysozyme is 11.1 and each molecule has approximately ten positive charges at $\mathrm{pH}$ values of 5 to 6 (Huang et al., 2007; Spassov \& Yan, 2008; Tanford \& Wagner, 1954). The distribution of ten charges over a surface of roughly $33 \mathrm{~nm}^{2} /$ lysozyme molecule corresponds to an average distance between charge sites of roughly $1.85 \mathrm{~nm}$, or slightly greater than the distance between charge sites on the clay. Furthermore, the surface of lysozyme comprises polar sites separated by hydrophobic patches similar to the distribution of polar and hydrophobic sites on smectites (Sivozhelezov et al., 2006).

Lysozyme is a fairly rigid globular protein. Prior structural and spectroscopic studies have established that its secondary structure is recalcitrant to structural modification (e.g. denaturation). Lysozyme is comprised of 129 amino acids and one measure of protein secondary and tertiary structure can be obtained through FTIR spectroscopy and analysis of the 'amide bands'. In studies of lysozyme sorbed on clay minerals, these bands indicate that the secondary structure remains intact on the clay surface (Szabo et al., 2007). However, these bands are sensitive indicators of conformational changes in larger and more flexible 'soft proteins', such as bovine serum albumin and chymotrypsin (Baron et al., 1999; Noinville et al., 2004; Servagent-Noinville et al., 2000). In addition to providing a large suite of complex molecules which function as surface/structural probes, these molecules can have a catalytic ability which opens the door for supported enzymes (Garwood et al., 1983; Mortland, 1984; Quiquampoix \& Burns, 2007).

\section{CLAY MINERALS AT THE \\ PARTICLE SCALE: ULTRATHIN HYBRID FILMS OF CLAY MINERALS}

The largest scale to be examined briefly in this review is the scale of the clay particles themselves. Particle-particle interactions have many effects in clay science that include molecular theories of clay swelling, nematic crystals, all aspects of clay-based/ modified rheology, liquefaction, and colloid assisted transport, to name a few. Interactions at this scale have been the subject of an excellent comprehensive review (Lagaly, 2006) and a prototypical example is given here to illustrate the relationship of interactions at this scale with the smaller scales shown in Fig. 1. The synthesis, characterization and manipulation of ultrathin hybrid films is presented here as an illustrative example of a relatively new area of particle-scale research in clay science (Ras et al., 2007b). Ultrathin hybrid films based on clay minerals are finding application in nanoscience and nanotechnology and consist of monolayer and multilayer hybrid nanofilms comprised of layers of smectite particles alternating with layers of functional molecules. In this area of research, clay particles can be organized into films through a number of methods including casting, spin coating, self-assembling (also called fuzzy assembling) or layer-by-layer deposition, and through the Langmuir-Blodgett (LB) method (Ras et al., 2007b). We limit the discussion to the application of the Langmuir-Blodgett method.

The initial application of the LB technique consisted of spreading a hydrophobic organo-clay complex dissolved in an organic solvent over water and allowing the organic solvent to evaporate (Inukai et al., 1994; Kotov et al., 1994). The approach that is currently being used involves spreading a cationic amphiphile dissolved in an organic solvent over a dilute aqueous suspension of clay particles as shown in Fig. 18 (Ras et al., 2003, 2004a,b,c, 2007a,b). The cationic head group of the amphilicic surfactant has a great affinity for the negatively charged clay surface. In addition, the 


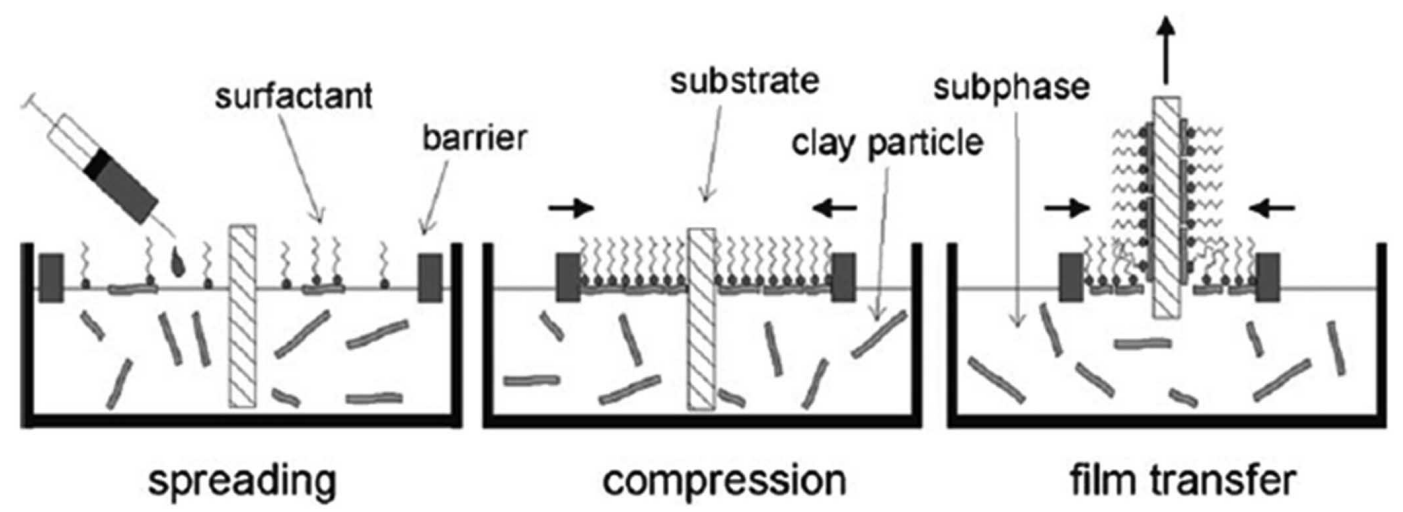

FIG. 18. The hybrid film deposition process of the Langmuir-Blodgett technique (Ras et al., 2007b).

long alkyl chain(s) of the surfactant are responsible for the molecular buoyancy of the clay-organic complex. In this approach, the insoluble amphilicic compounds 'pickup' elementary clay particles. The method is dependent on having dispersed individual clay particles in the aqueous solution. Upon compression in the Langmuir trough, the clayorganic complexes floating on the surface of the water are compressed to a desired surface pressure and removed from the LB trough on a solid substrate as shown in Fig. 18. A number of head groups have been used to prepare ultrathin hybrid clay films and some of these are illustrated in Fig. 19. The long alkyl chains, designated by R, are not shown in the structure. The structure and electrostatic potential map of 3,3'-dioctadecyl oxacarbocyanine (abbreviated as OXA) are shown on the left side of Fig. 20 and the OXA-smectite complex on the right. The $\mathrm{C}_{16}$ chains of OXA provide the molecular buoyancy of the clay-organic complex at the air-water interface with the head group of OXA electrostatically tethered to the clay surface.

One of the goals of nanoscience and nanotechnology is to produce new functional nanomaterials with low cost and high added value. At the same time, however, the amphiphilic surfactants provide a unique class of probe molecules to study clay surfaces. Furthermore, the resultant ultrathin hybrid clay films (UHCFs), consisting of one layer of $1 \mathrm{~nm}$ thick clay particles opens up new opportunities to study the surface chemistry of clay minerals and to study particle-particle interactions. The synthesis and characterization of ultrathin hybrid clay films have been the subject of a recent review (Ras et al., 2007b) and are briefly summarized here. Perhaps the most useful characterization method for studying UHCFs is AFM because it provides a direct means of visualizing the size and shape of individual $1 \mathrm{~nm}$ thick elementary clay particles, the organization of clay particles in the UHCF, and information about the thickness of the clay film and stacking of multiple clay particles on top of each other. Polarized FTIR methods have provided detailed insight into the orientation of the clay particles within the film, as well as on the optical density of the UHCF, information about the orientation of the amphiphilic cation on the clay surface, as well as the ordering of the alkyl chains. Fluorescence spectroscopy provides a sensitive method for studying the organization of, and interaction between, amphiphilic molecules with strong UV absorption features (e.g. cationic dyes like OXA or RhB18). Although at the limit of sensitivity, X-ray methods are being successfully applied to study UHCFs and multi-layered UHCFs. Yamagishi and co-workers have further exploited UHCFs by subsequent modification of the clay monolayers with various cationic metal complexes towards producing functional materials (Umemura et al., 2002) One such application involves the separation of chiral molecules on clay surfaces.

\section{CONCLUDING REMARKS}

Considering the spatial length scales associated with $\mathrm{H}$ bonding, clay-water and clay-organic interactions provide a useful framework to better understand these complex materials. The small length scale associated with the naturally occurring 


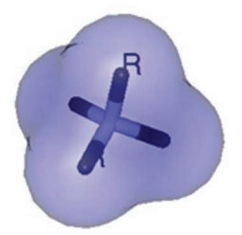

Dimethyl dioctadecyl-ammonium DMDODA MW: 551.06

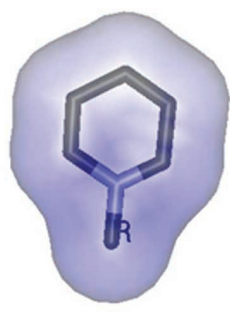

1-hexadecylpyridinium HDP - MW: 304.54

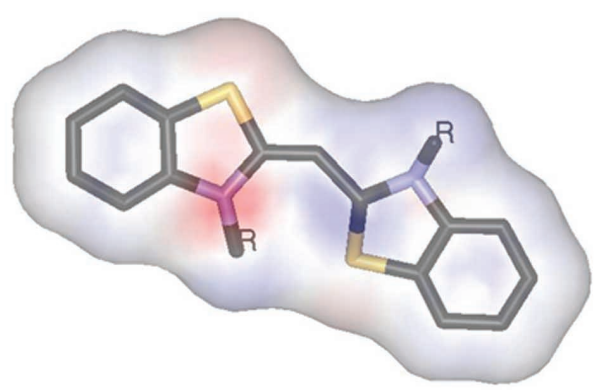

2-methyl-3,3'-dioctadecyl-2,3,2',3'-tetrahydro2,2'-meth anylylidene-bis-benzothiazole MBT MW: 803.38

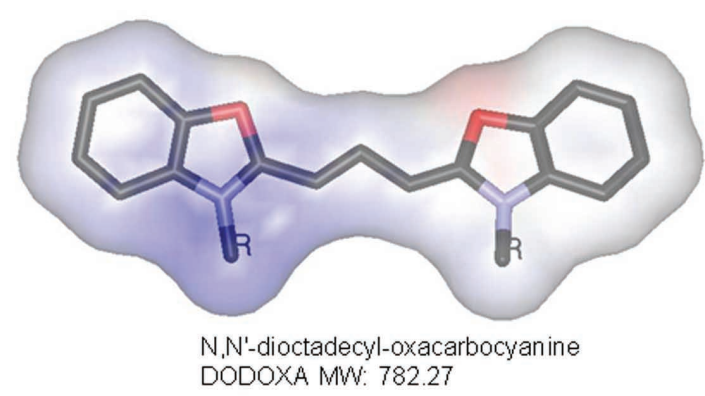

DODOXA MW: 782.27

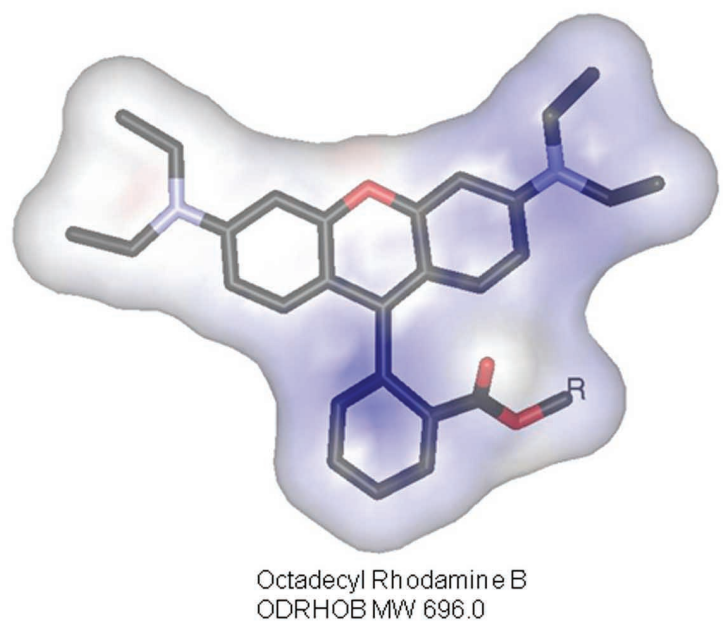

FIG. 19. Various cationic head groups used to prepare ultrathin hybrid films with clay minerals.

nanomaterials is the basis for their profound influence of a wide range of processes. At the same time, however, understanding their structure and surface chemistry requires new tools adapted to the study of nanomaterials and interfacial processes. It is now well established that molecular spectroscopy combined with sorption, structural, and computational tools are the methods of choice. At the sub-nanometre length scale, $\mathrm{H}$ bonding interactions of the structural $\mathrm{OH}$ groups of clay minerals play a key role in defining the size, shape, geochemical stability and surface chemistry of $1: 1$ phyllo-silicates. In addition, these 'reporter groups' are currently being used to study particle size and shape, structural disorder, temperature and pressure effects as well as their interaction with water and organic solutes. Although difficult to study because of their small abundance relative to the total $\mathrm{OH}$ population, exposed surface $\mathrm{OH}$ groups, especially under-coordinated $\mathrm{OH}$ groups at the broken edges, exert a profound influence on the rheological properties of clays as well as their ability to bind metals and oxyanions. For both structural and surface $\mathrm{OH}$ groups, the H-bonding interactions they participate in which effectively operate at a scale of $<0.4 \mathrm{~nm}$, defines the size, shape and many aspects of the overall surface chemistry of clay minerals.

Hydrogen bonding, along with other types of chemical forces, also plays critical roles in determining how $\mathrm{H}_{2} \mathrm{O}$ molecules interact with clay minerals. $\mathrm{H}_{2} \mathrm{O}$ molecules are always associated with clay minerals because of their small size, expansive surface area and electrically charged nature. The complexity of clay-water interactions is examined on the basis of the type(s) of surface present, the electrically charged nature of the clay surface and the type of inorganic cations present. In the case of smectites, the clustering of $\mathrm{H}_{2} \mathrm{O}$ molecules around exchangeable cations is a type of hydrophilic molecular probe over a spatial length scale that extends from the size of $\mathrm{H}_{2} \mathrm{O}$ molecules $(\sim 0.3 \mathrm{~nm})$ to the limit of clay swelling $(\sim 10 \mathrm{~nm})$. To a large extent, water defines the surface chemistry of clay 


\section{3,3'-dioctadecyl oxacarbocyanine (OXA)}
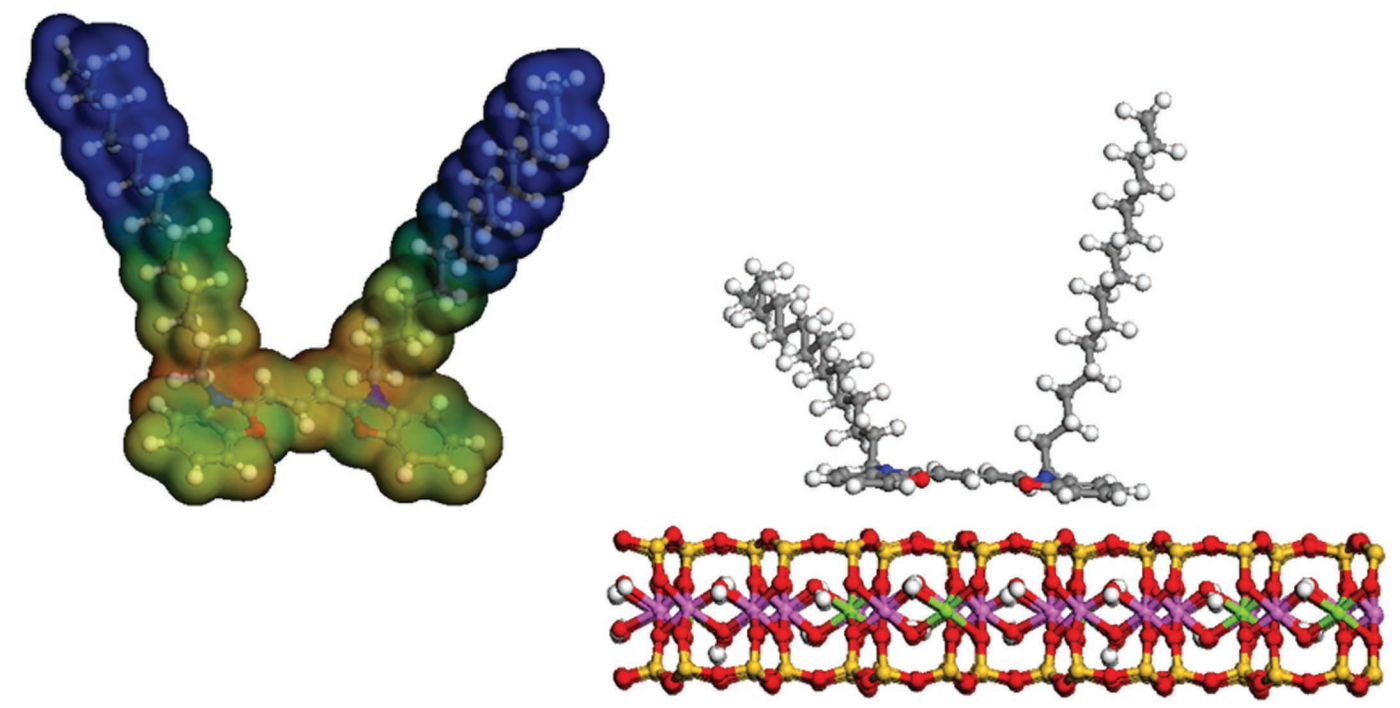

FIG. 20. The structure and electrostatic potential map of 3,3'-dioctadecyl oxacarbocyanine (OXA) is shown on the left side and the OXA-smectite complex on the right.

minerals. At the same time, however, these interactions play a moderating role in governing how organic solutes will interact with clay minerals. Organic solutes provide a diverse suite of molecular probes to explore clay surfaces on the basis of their size and surface chemistry. By definition, water is the prototypical hydrophilic surface probe. Polar surface interactions can also be explored using small polar organic solutes, such as the small polar compounds that can intercalate kaolin group minerals (e.g. hydrazine).

In the case of 2:1 phyllosilicates with isomorphous substitution, the siloxane surface has both a hydrophilic and a hydrophobic character. $\mathrm{H}_{2} \mathrm{O}$ molecules clustered around exchangeable cations provide one type hydrophilic probe of these surfaces. In addition, organic solutes with varying size, shape and polarity provide a useful set of probe molecules. In the case of neutral organic contaminants (NOCs) which have polar functional groups (e.g. nitroaromatics or triazines), these molecules can be stabilized in clay interlayers through the combined interaction of charge-dipole interactions and through van der Waals interactions with the neutral portion of the siloxane surface. For these molecules, sorption is governed by the charge density of the clay, location of charge deficit in the clay structure, charge and enthalpy of hydration of exchangeable cation, number and type of polar functional group of the organic solute as well as size and planarity of the solute. Recently, these concepts have been further extended by observation that certain strongly hydrophobic compounds have a great affinity for smectite clay minerals. In particular, dibenzo-p-dioxin provides an interesting hydrophobic probe molecule that shows a great affinity for certain smectites from aqueous suspension when exchanged with weakly hydrated monovalent cations. At the next larger scale (2 to $6 \mathrm{~nm}$ ), complex biological molecules show a great affinity for clay minerals depending on their overall size and isoelectric point. For these types of molecules, stabilization on clay minerals is attributed to both polar and nonpolar interactions and is controlled by the overall charge and size of the protein.

The exceptionally great affinity of organic cations and protonated organic bases for clay minerals with permanent charge sites resulting from isomorphous substitution is well known and 
attributed to both the nature of the clay surface and to the thermodynamics of cation hydration. For the past 50 years, clay scientists have exploited some level of 'size matching' to develop clay-organic complexes, mainly in the area of organoclays. A relatively new area that is based on this same great affinity of organic cations for clay minerals is in the synthesis of ultrathin hybrid clay films. In this case, cationic head groups of varying size, shape and charge, combined with long alkyl chains, function as surfactant probe molecules. These molecules are generally of the order of about $2 \mathrm{~nm}$ in length but collectively they 'float' individual clay particles to the surface of the air-water interface and subsequent isolation in LB films. This approach is providing a new set of tools to study the organization and characterization of clay minerals.

\section{ACKNOWLEDGMENTS}

The paper is submitted as a contribution in honour of George Brown and his pioneering work in the area of clay mineralogy. The author would like express sincere appreciation to Stephen Agnew, David Bish, Stephen Boyd, Hui Li, Robin Ras, Robert Schoonheydt, Garrison Sposito, Brian Teppen and Shan-Li Wang for their friendship, scientific inspiration and valued collaborations. The project was supported, in part, by grant P42 ES004911 from the National Institute of Environmental Health Sciences (NIEHS). The contents are solely the responsibility of the author and do not necessarily represent the official views of NIEHS or NIH.

\section{REFERENCES}

Ahn, D.J. \& Franses E.I. (1992) Orientations of chain axes and transition moments in Langmuir-Blodgett monolayers deterimined by polarized FTIR-ATR spectroscopy. Journal of Physical Chemistry, 96, 9952-9959.

Albert J.T. \& Harter R.D. (1973) Adsorption of lysozyme and ovalbumin by clay - effect of clay suspension $\mathrm{pH}$ and clay mineral type. Soil Science, 115, 130-136.

Altaner S.P., Weiss C.A. \& Kirkpatrick R.J. (1988) Evidence from 29Si NMR for the structure of mixedlayer illite/smectite clay minerals. Nature, 331, 699-702.

Bailey S.W. (1988) Polytypism of 1-1 layer silicates. Pp. 9-27 in: Reviews in Mineralogy, 19 (S.W. Bailey, editor). Mineralogical Society of America, Washington DC, USA.

Balan E., Saitta A.M. Mauri, F. \& Calas G. (2001) First- principles modeling of the infrared spectrum of kaolinite. American Mineralogist, 86, 1321-1330.

Balan E., Lazzeri M., Saitta A.M., Allard T., Fuchs Y. \& Mauri F. (2005) First-principles study of OHstretching modes in kaolinite, dickite, and nacrite. American Mineralogist, 90, 50-60.

Balan E., Lazzeri M., Morin G. \& Mauri F. (2006) Firstprinciples study of the $\mathrm{OH}$-stretching modes of gibbsite. American Mineralogist, 91, 115-119.

Balan E., Lazzeri M., Mauri F. \& Calas G. (2007) Structure, reactivity and spectroscopic properties of minerals from lateritic soils: insights from ab initio calculations. European Journal of Soil Science, 58, 870-881.

Baron M.H., Revault M., Servagent-Noinville S., Abadie J. \& Quiquampoix H. (1999) Chymotrypsin adsorption on montmorillonite: Enzymatic activity and kinetic FTIR structural analysis. Journal of Colloid and Interface Science, 214, 319-332.

Barriuso E., Laird D.A., Koskinen W.C. \& Dowdy R.H. (1994) Atrazine desorption from smectites. Soil Science Society of America Journal, 58, 1632-1638.

Beaufort D., Cassagnabere A., Petit S., Lanson B., Berger G., Lacharpagne J.C. \& Johansen H. (1998) Kaolinite-to-dickite reaction in sandstone reservoirs. Clay Minerals, 33, 297-316.

Belarbi H., Haouzi A., Douillard J.M., Giuntini, J.C. \& Henn F. (2007) Hydration of a $\mathrm{Na}^{+}$-montmorillonite studied by thermally stimulated depolarization current. Journal of Colloid and Interface Science, 308, 216-221.

Bergaya F. \& Lagaly G. (2006) General introduction: clays, clay minerals and clay science. Pp. 1-18 in: Handbook of Clay Science (F. Bergaya, B.K.G. Theng \& G. Lagaly, editors). Elsevier, Amsterdam, The Netherlands.

Bish D.L. (1993) Rietveld refinement of the kaolinite structure at $1.5 \mathrm{~K}$. Clays and Clay Minerals, 41, 738-744.

Bish D.L. \& Johnston C.T. (1993) Rietveld refinement and Fourier transform infrared spectroscopic study of the dickite structure at low temperature. Clays and Clay Minerals, 41, 297-304.

Bookin A.S., Drits V.A. Plançon A. \& Tchoubar C. (1989) Stacking faults in kaolin-group minerals in the light of real structural features. Clays and Clay Minerals, 37, 297-307.

Bordallo H.N., Aldridge L.P., Churchman G.J., Gates W.P., Telling M.T.F., Kiefer K., Fouquet P., Seydel T. \& Kimber S.A.J. (2008) Quasi-elastic neutron scattering studies on clay interlayer-space highlighting the effect of the cation in confined water dynamics. Journal of Physical Chemistry C, 112, 13982-13991.

Bowers G.M., Bish, D.L. \& Kirkpatrick R.J. (2008) $\mathrm{H}_{2} \mathrm{O}$ and cation structure and dynamics in expandable clays: H-2 and K-39 NMR investigations of 
hectorite. Journal of Physical Chemistry C, 112, 6430-6438.

Boyd S.A. \& Mortland M.M. (1985) Urease activity on a clay-organic complex. Soil Science Society of America Journal, 49, 619-622.

Boyd S.A., Sheng G., Teppen B.J. \& Johnston C.T. (2001) Mechanisms for the adsorption of substituted nitrobenzenes by smectite clays. Environmental Science \& Technology, 35, 4227-4234.

Brandt K.B., Elbokl T.A. \& Detellier C. (2003) Intercalation and interlamellar grafting of polyols in layered aluminosilicates. D-Sorbitol and adonitol derivatives of kaolinite. Journal of Materials Chemistry, 13, 2566-2572.

Brindley G.W. \& Ertem G. (1971) Prepartion and solvation properties of some variable charge montmorillonites. Clays and Clay Minerals, 19, 399-404.

Brindley G.W. \& Robinson K. (1946) The structure of kaolinite. Mineralogical Magazine, 27, 242-253.

Bromley K.M., Patil A.J., Seddon A.M., Booth P. \& Mann S. (2007) Bio-functional mesolamellar nanocomposites based on inorganic/polymer intercalation in purple membrane (bacteriorhodopsin) films. Advanced Materials, 19, 2433-2438.

Brown G.E., Henrich V.E., Casey W.H., Clark D.L., Eggleston C., Felmy A., Goodman D.W., Gratzel M., Maciel G., McCarthy M.I., Nealson K.H., Sverjensky D.A., Toney M.F. \& Zachara J.M. (1999) Metal oxide surfaces and their interactions with aqueous solutions and microbial organisms. Chemical Reviews, 99, 77-174.

Brown G.E., Catalano J.G., Templeton A.S., Trainor T.P., Farges F., Bostick B.C., Kendelewicz T., Doyle C.S., Spormann A.M., Revill K., Morin G., Juillot F. \& Calas G. (2005) Environmental interfaces, heavy metals, microbes, and plants: Applications of XAFS spectroscopy and related synchrotron radiation methods to environmental science. Physica Scripta, T115, 80-87.

Buswell A.M., Krebs K. \& Rodebush W.H. (1937) Infrared studies. III. Absorption bands of hydrogels between 2.5 and 3.5 micrometers. Journal of the American Chemical Society, 59, 2603-2605.

Butler I.S. \& Frost R.L. (2006) An overview of the highpressure vibrational spectra of clays and related minerals. Applied Spectroscopy Reviews, 41, 449-471.

Carey D.M. \& Korenowski G.M. (1998) Measurement of the Raman spectrum of liquid water. Journal of Chemical Physics, 108, 2669-2675.

Cebula D.J., Thomas R.K. \& White J.W. (1981) Diffusion of water in Li-montmorillonite studied by quasielastic neutron scattering. Clays and Clay Minerals, 29, 241-248.

Chang F.R.C., Skipper N.T. \& Sposito G. (1997) Monte Carlo and molecular dynamics simulations of inter- facial structure in lithium-montmorillonite hydrates. Langmuir, 13, 2074-2082.

Chappell M.A., Laird D.A., Thompson M.L., Li H., Teppen B.J., Aggarwal V., Johnston C.T. \& Boyd S.A. (2005) Influence of smectite hydration and swelling on atrazine sorption behavior. Environmental Science \& Technology, 39, 3150-3156.

Chen G.J., Yen M.C., Wang J.M., Lin J.J. \& Chiu H.C. (2008) Layered inorganic/enzyme nanohybrids with selectivity and structural stability upon interacting with biomolecules. Bioconjugate Chemistry, 19, $138-144$.

Clementz D.M., Pinnavaia T.J. \& Mortland M.M. (1973) Stereochemistry of hydrated copper(II) ions on the interlamellar surfaces of layer silicates. An electron spin resonance study. Journal of Physical Chemistry, 77, 196-200.

Clementz D.M., Mortland M.M. \& Pinnavaia T.J. (1974) Properties of reduced charge montmorillonites: Hydrated $\mathrm{Cu}(\mathrm{II})$ ions as a spectroscopic probe. Clays and Clay Minerals, 22, 49-57.

Costanzo P.M. \& Giese R.F. (1985) Dehydration of synthetic hydrated kaolinites: a model for the dehyration of halloysite $(10 \AA)$. Clays and Clay Minerals, 33, 415-423.

Costanzo P.M. \& Giese R.F. (1990) Ordered and disordered organic intercalates of 8.4-A synthetically hydrated kaolinte. Clays and Clay Minerals, 38, 160-170.

Costanzo P.M., Giese R.F., Lipsicas M. \& Straley C. (1982) Synthesis of a quasi-stable kaolinite and heatcapacity of interlayer water. Nature, 296, 549-551.

Cruz M.D.R. \& Franco F. (2000) Thermal behavior of the kaolinite-hydrazine intercalation complex. Clays and Clay Minerals, 48, 63-67.

Darder M., Aranda P. \& Ruiz-Hitzky E. (2007) Bionanocomposites: A new concept of ecological, bioinspired, and functional hybrid materials. Advanced Materials, 19, 1309-1319.

Davis J.A. \& Kent D.B. (1990) Surface complexation modeling in aqueous geochemistry. Pp. 177-260 in: Mineral-Water Interface Geochemistry. Reviews in Mineralogy, 23 (M.F. Hochella \& A.F. White). Mineralogical Society of America, Washington D.C., USA.

De Cristofaro A. \& Violante A. (2001) Effect of hydroxy-aluminium species on the sorption and interlayering of albumin onto montmorillonite. Applied Clay Science, 19, 59-67.

de Donato P., Cheilletz A., Barres O. \& Yvon J. (2004) Infrared spectroscopy of OD vibrators in minerals at natural dilution: hydroxyl groups in talc and kaolinite, and structural water in beryl and emerald. Applied Spectroscopy, 58, 521-527.

De Oliveira M.F., Johnston C.T., Premachandra G.S., Teppen B.J., Li H., Laird D.A., Zhu D.Q. \& Boyd 
S.A. (2005) Spectroscopic study of carbaryl sorption on smectite from aqueous suspension. Environmental Science \& Technology, 39, 9123-9129.

Delville A. (1992) Structure of liquids at a solid interface: an application to the swelling of clay by water. Langmuir, 8, 1796-1805.

Denison M.S. \& Nagy S.R. (2003) Activation of the aryl hydrocarbon receptor by structurally diverse exogenous and endogenous chemicals. Annual Review of Pharmacology and Toxicology, 43, 309-334.

Dera P., Prewitt C.T., Japel S., Bish D.L. \& Johnston C.T. (2003) Pressure-controlled polytypism in hydrous layered materials. American Mineralogist, 88, $1428-1435$.

Downs R.T. \& Hall-Wallace M. (2003) The American Mineralogist crystal structure database. American Mineralogist, 88, 247-250.

Du Q., Freysz E. \& Shen Y.R. (1994a) Surface vibrational spectroscopic studies of hydrogen bonding and hydrophobicity. Science, 264, 826-828.

Du Q., Freysz E. \& Shen Y.R. (1994b) Vibrational spectra of water molecules at quartz-water interfaces. Physical Review Letters, 72, 238-241.

Dubois P. (2007) Layered silicate polymer nanocomposites: melt-blending versus intercalative polymerization. Pp. 33-60 in: Clay-based Polymer Nanocomposites (CPN) (K.A. Carrado \& F. Bergaya, editors). The Clay Minerals Society, Chantilly, VA, USA.

Eisenthal, K.B. (1996) Liquid interfaces probed by second-harmonic and sum-frequency spectroscopy. Chemical Reviews, 96, 1343-1360.

Elbok1 T.A. \& Detellier C. (2008) Intercalation of cyclic imides in kaolinite. Journal of Colloid and Interface Science, 323, 338-348.

Ensminger L.E. \& Gieseking J.E. (1939) The adsorption of proteins by montmorillonitic clays. Soil Science, 48, 467-473.

Ensminger L.E. \& Gieseking J.E. (1941) The absorption of proteins by montmorillonitic clays and its effect on base-exchange capacity. Soil Science, 51, 125-132.

Ensminger L.E. \& Gieseking J.E. (1942) Resistance of clay-adsorbed proteins to proteolytic hydrolysis. Soil Science, 53, 205-209.

Falk M. (1984) The frequency of the H-O-H bending fundamental in solids and liquids. Spectrochimica Acta Part A-Molecular and Biomolecular Spectroscopy, 40, 43-48.

Farmer V.C. (1998) Differing effects of particle size and shape in the infrared and Raman spectra of kaolinite. Clay Minerals, 33, 601-604.

Farmer V.C. (2000) Transverse and longitudinal crystal modes associated with $\mathrm{OH}$ stretching vibrations in single crystals of kaolinite and dickite. Spectrochimica Acta Part A-Molecular and Biomolecular Spectroscopy, 56, 927-930.
Farmer V.C. \& Mortland M.M. (1966) Infrared study of the coordination of pyridine and water to exchangeable cations in montmorillonite and saponite. Journal of the Chemical Society, 1966A, 344-351.

Feller D., Glendening E.D., Woon D.E. \& Feyereisen M.W. (1995) An extended basis-set ab-initio study of alkali-metal cation-water clusters. Journal of Chemical Physics, 103, 3526-3542.

Fernandez M., Serratosa J.M. \& Johns W.D. (1970) Perturbation of the stretching vibration of $\mathrm{OH}$ groups in phyullosillicates by the interlayer cations. Reunion Hispano-Belga de Minerales de la Arcilla, 163-167.

Ferrario J. \& Byrne C. (2000) The concentration and distribution of 2,3,7,8-dibenzo-p-dioxins/-furans in chickens. Chemsophere, 40, 221-224.

Frost R.L. \& Kloprogge J.T. (2000) Raman spectroscopy of nacrite single crystals at 298 and $77 \mathrm{~K}$. Spectrochimica Acta Part A-Molecular and Biomolecular Spectroscopy, 56, 931-939.

Fukuda J. \& Shinoda K. (2008) Coordination of water molecules with $\mathrm{Na}+$ cations in a beryl channel as determined by polarized IR spectroscopy. Physics and Chemistry of Minerals, 35, 347-357.

Gale P.A. (2000) Anion coordination and anion-directed assembly: highlights from 1997 and 1998 . Coordination Chemistry Reviews, 199, 181-233.

Garwood G.A., Mortland M.M. \& Pinnavaia T.J. (1983) Immobilization of glucose oxidase on montmorillonite clay: hydrophobic and ionic modes of binding. Journal of Molecular Catalysis, 22, 153-163.

Gianfreda L., Rao M.A., Sannino F., Saccomandi F. \& Violante A. (2002) Enzymes in soil: Properties, behavior and potential applications. Soil MineralOrganic Matter-Microorganism Interactions and Ecosystem Health, 28B, Ecological Significance of the Interactions Among Clay Minerals, Organic Matter and Soil Biota, 301-327.

Glendening E.D. \& Feller D. (1995) Cation-water interactions: the $M^{+}\left(\mathrm{H}^{2} \mathrm{O}\right)_{\mathrm{n}}$ clusters for alkali metals, $M=\mathrm{Li}, \mathrm{Na}, \mathrm{K}, \mathrm{Rb}$, and Cs. Journal of Physical Chemistry, 99, 3060-3067.

Glendening E.D. \& Feller D. (1996) Dication-water interactions: $M\left({ }^{2+}\right)\left(\mathrm{H}_{2} \mathrm{O}\right)_{(\mathrm{n})}$ clusters for alkaline earth metals, $M=\mathrm{Mg}, \mathrm{Ca}, \mathrm{Sr}, \mathrm{Ba}$, and $\mathrm{Ra}$. Journal of Physical Chemistry, 100, 4790-4797.

Guven N. (1988) Smectites. Pp. 497-559 in: Hydrous phyllosilicates (exclusive of micas) (S.W. Bailey, editor). American Mineralogical Society, Washington DC, USA.

Haack E.A., Johnston C.T. \& Maurice P.A. (2008) Mechanisms of siderophore sorption to smectite and siderophore-enhanced release of structural $\mathrm{Fe}^{3+}$. Geochimica et Cosmochimica Acta, 72, 3381-3397.

Haderlein S.B. \& Schwarzenbach R.P. (1993) Adsorption of substituted nitrobenzenes and nitrophenols to mineral surfaces. Environmental Science \& Technology, 27, 316-326. 
Haderlein S.B., Weissmahr K.W. \& Schwarzenbach R.P. (1996) Specific adsorption of nitroaromatic: Explosives and pesticides to clay minerals. Environmental Science \& Technology, 30, 612-622.

Harter R.D. (1975) Effect of exchange cations and solution ionic-strength on formation and stability of smectite-protein complexes. Soil Science, 120, 174-181.

Harter R.D. \& Stotzky G. (1971) Formation of clayprotein complexes. Soil Science Society of America Proceedings, 35, 383-389.

Hayward D.G. \& Bolger P.M. (2005) Tetrachlorodibenzo-p-dioxin in baby food made from chicken produced before and after the termination of ball clay use in chicken feed in the United States. Environmental Research, 99, 307-313.

Hayward D.G., Nortrup D., Gardner A. \& Clower M. (1999) Elevated TCDD in chicken eggs and farmraised catfish fed a diet with ball clay from a southern United States mine. Environmental Research, 81, 248-256.

Heller-Kallai L. \& Rozenson I. (1981) The use of Mossbauer-spectroscopy of iron in clay mineralogy. Physics and Chemistry of Minerals, 7, 223-238.

Hendricks S.B. (1929) Diffraction of X-radiation from some crystalline aggregates. Zeitschrift für Kristallographie, 71, 273-275.

Hochella M.F. (2006) The case for nanogeoscience. Progress in Convergence: Technologies for Human Wellbeing, 1093, 108-122.

Hochella M.F. (2008) Nanogeoscience: from origins to cutting-edge applications. Elements, 4, 373-379.

Hofmann U. \& Klemen R. (1950) Verlust der Austauschf'fihigkeit yon Lithiumionen an Bentonit durch Erhitzung. Zeitschrift für Anorganische und Allgemeine Chemie, 262, 95-99.

Holtz M., Solin S.A. \& Pinnavaia T.J. (1993) Effect of pressure on the Raman vibrational modes of layered aluminosilicate compounds. Physical Review, 48, 312-317.

Huang E., Li A. \& Xu J. (1996) High-pressure phase transition in $\mathrm{Al}(\mathrm{OH})_{3}$ : Raman and X-ray observations. Geophysical Research Letters, 23, 3083-3086.

Huang E., Lin J.F., Xu J., Huang T., Jean Y.-C. \& Sheu H.-S. (1999) Compression studies of gibbsite and its high-pressure polymorph. Physics and Chemistry of Minerals, 26, 576-583.

Huang Y.S., Jeng U.S., Shiu Y.J., Lai Y.H. \& Sun Y.S. (2007) Charge interaction and temperature effects on the solution structure of lysozyme as revealed by small-angle X-ray scattering. Journal of Applied Crystallography, 40, S165-S169.

Inukai K., Hotta Y., Taniguchi M., Tomura S. \& Yamagishi A. (1994) Formation of a clay monolayer at an air-water-interface. Journal of the Chemical Society-Chemical Communications, 959-959.
Jaynes W.F., Traina S.J., Bigham J.M. \& Johnston C.T. (1992) Preparation and characterization of reducedcharge hectorites. Clays and Clay Minerals, 40, $397-405$.

Jena K.C. \& Hore D.K. (2009) Variation of ionic strength reveals the interfacial water structure at a charged mineral surface. Journal of Physical Chemistry C, 113, 15364-15372.

Johnston C.T. (1996) Sorption of organic compounds on clay minerals: A surface functional group approach. Pp. 1-44 in: Organic Pollutants in the Environment (B. Sawhney, editor). Clay Minerals Society, Boulder, CO, USA.

Johnston C.T. \& Premachandra G.S. (2001) Polarized ATR-FTIR study of smectite in aqueous suspension. Langmuir, 17, 3712-3718.

Johnston C.T. \& Stone D.A. (1990) Influence of hydrazine on the vibrational modes of kaolinite. Clays and Clay Minerals, 38, 121-128.

Johnston C.T. \& Tombacz E. (2002) Surface chemistry of soil minerals. Pp. 37-67 in: Soil Mineralogy with Environmental Applications (J.B. Dixon \& D.G. Schulze, editors). Soil Science Society of America, Madison, Wisconsin, USA.

Johnston C.T., Sposito G., Bocian D.F. \& Birge R.R. (1984) Vibrational spectroscopic study of the interlamellar kaolinite-dimethylsu0lfoxide complex. Journal of Physical Chemistry, 88, 5959-5964.

Johnston C.T., Sposito G. \& Birge R.R. (1985) Raman spectroscopic study of kaolinite in aqueous suspension. Clays and Clay Minerals, 33, 483-489.

Johnston C.T., Stone D.A. \& Applewhite L.A. (1987) Vibrational spectroscopic study of the kaolinitehydrazine intercalation complex. Pp. 118-127 in: The Third Conference on the Environmental Chemistry of Hydrazine Fuels, Panama City, FL 15-17 Sept. 1987. ESL-TR-87-74.

Johnston C.T., Agnew S.F. \& Bish D.L. (1990) Polarized single-crystal Fourier-transform infrared microscopy of Ouray dickite and Keokuk kaolinite. Clays and Clay Minerals, 38, 573-583.

Johnston C.T., Sposito G. \& Erickson C. (1992) Vibrational probe studies of water interactions with montmorillonite. Clays and Clay Minerals, 40, $722-730$.

Johnston C.T., Sposito G. \& Earl W.L. (1993) Surface spectroscopy of environmental particles by Fourier transform infrared and nuclear magnetic resonance spectroscopy. Pp. 1-36 in: Environmental Particles. Environmental Analytical and Physical Chemistry Series, 2 (J. Buffle \& H.P. Van Leeuwen, editors) Lewis Publ., Boca Raton.

Johnston C.T., Helsen J., Schoonheydt R.A., Bish D.L. \& Agnew S.F. (1998) Single crystal Raman spectroscopic study of dickite. American Mineralogist, 83, $75-84$.

Johnston C.T., Bish D.L., Eckert J. \& Brown L.A. 
(2000) Infrared and inelastic neutron scattering study of the 1.03-and $0.95-\mathrm{nm}$ kaolinite-hydrazine intercalation complexes. Journal of Physical Chemistry $B, \mathbf{1 0 4}, 8080-8088$.

Johnston C.T., Oliveira M.F.D., Sheng G. \& Boyd S.A. (2001) Spectroscopic study of nitroaromatic-smectite sorption mechanisms. Environmental Science \& Technology, 35, 4767-4772.

Johnston C.T., Sheng G., Teppen B.J., Boyd S.A. \& De Oliveira M.F. (2002a) Spectroscopic study of dinitrophenol herbicide sorption on smectite. Environmental Science \& Technology, 36, 5067-5074.

Johnston C.T., Wang S.L., Bish D.L., Dera P., Agnew S.F. \& Kenney J.W. (2002b) Novel pressure-induced phase transformations in hydrous layered materials. Geophysical Research Letters, 29, art-1770.

Johnston C.T., Boyd S.A., Teppen B.J. \& Sheng G. (2004) Sorption of nitroaromatic compounds on clay surfaces. Pp. 155-189 in: Handbook of Layered Materials (S.M. Auerbach, K.A. Carrado \& P.K. Dutta, editors). Marcell Dekker Inc., New York, USA.

Johnston C.T., Elzea Kogel J., Bish D.L., Kogure T. \& Murray H. (2008) Low-temperature FTIR study of kaolin-group minerals. Clays and Clay Minerals, 56, 470-485.

Joussein E., Petit S., Churchman J., Theng B., Righi D. \& Delvaux B. (2005) Halloysite clay minerals - a review. Clay Minerals, 40, 383-426.

Kameda J., Yamagishi A. \& Kogure T. (2005) Morphological characteristics of ordered kaolinite: investigation using electron back-scattered diffraction. American Mineralogist, 90, 1462-1465.

Kameda J., Saruwatari K., Beaufort D. \& Kogure T. (2008) Textures and polytypes in vermiform kaolins diagenetically formed in a sandstone reservoir: a FIB-TEM investigation. European Journal of Mineralogy, 20, 199-204.

Kogure T. \& Inoue A. (2005a) Determination of defect structures in kaolin minerals by high-resolution transmission electron microscopy (HRTEM). American Mineralogist, 90, 85-89.

Kogure T. \& Inoue A. (2005b) Stacking defects and long-period polytypes in kaolin minerals from a hydrothermal deposit. European Journal of Mineralogy, 17, 465-473.

Kogure T., Hybler J. \& Durovic S. (2001) A HRTEM study of cronstedtite: determination of polytypes and layer polarity in trioctahedral 1:1 phyllosilicates. Clays and Clay Minerals, 49, 310-317.

Kogure T., Elzea-Kogel J., Johnston C.T. \& Bish D.L. (2010) Stacking disorder in a sedimentary kaolinite. Clays and Clay Minerals, 58, 62-71.

Kotov N.A., Meldrum F.C., Fendler J.H., Tombacz E. \& Dekany I. (1994) Spreading of clay organo-complexes on aqueous solutions: construction of
Langmuir-Blodgett clay organocomplex multilayer films. Langmuir, 10, 3797-3804.

Kuroda K., Hiraguri K., Komori Y., Sugahara Y., Mouri H. \& Uesu Y. (1999) An acentric arrangement of pnitroaniline molecules between the layers of kaolinite. Chemical Communications, 2253-2254.

Lagaly G. (2006) Colloid clay science. Pp. 141-245 in: Developments in Clay Science, Handbook of Clay Science (F. Bergaya \& B.K.G. Theng, editors). Elsevier, Amsterdam, The Netherlands.

Lagaly G. \& Malberg R. (1990) Disaggregation of alkylammonium montmorillonites in organic-solvents. Colloids and Surfaces, 49, 11-27.

Lagaly G., Ogawa M. \& Dekany I. (2006) Clay mineral organic interactions. Pp. 309-377 in: Developments in Clay Science, Handbook of Clay Science. (F. Bergaya \& B.K.G. Theng, editors). Elsevier, Amsterdam, The Netherlands.

Laird D.A. (2006) Influence of layer charge on swelling of smectites. Applied Clay Science, 34, 74-87.

Laird D.A., Barriuso E., Dowdy R.H. \& Koskinen W.C. (1992) Adsorption of atrazine on smectites. Soil Science Society of America Journal, 56, 62-67.

Lanson B., Beaufort D., Berger G., Bauer A., Cassagnabere A. \& Meunier A. (2002) Authigenic kaolin and illitic minerals during burial diagenesis of sandstones: a review. Clay Minerals, 37, 1-22.

Ledoux R.L. \& White J.L. (1964) Infrared study of selective deuteration of kaolinite and halloysite at room temperature. Science, 145, 47-49.

Ledoux R.L. \& White J.L. (1966) Infrared studies of hydrogen bonding interaction between kaolinite surfaces and intercalated potassium acetate, hydrazine, formamide, and urea. Journal of Colloid and Interface Science, 21, 127-152.

Letaief S., Tonle I.K., Diaco T. \& Detellier C. (2008) Nanohybrid materials from interlayer functionalization of kaolinite. Application to the electrochemical preconcentration of cyanide. Applied Clay Science, 42, 95-101.

Libowitzky E. (1999) Correlation of O-H stretching frequencies and $\mathrm{O}-\mathrm{H} \cdots \mathrm{O}$ hydrogen bond lengths in minerals. Monatshefte für Chemie, 130, 1047-1059.

Lipsicas M., Raythatha R., Giese R.F. \& Costanzo P.M. (1986) Molecular motions, surface interactions, and stacking disorder in kaolinite intercalates. Clays and Clay Minerals, 34, 635-644.

Liu C., Li H., Teppen B.J., Johnston C.T. \& Boyd S.A. (2009) Mechanisms associated with the high adsorption of dibenzo-p-dioxin from water by smectite clays. Environmental Science \& Technology, 43, 2777-2783.

Logsdon S. \& Laird D. (2004) Cation and water content effects on dipole rotation activation energy of smectites. Soil Science Society of America Journal, 68, 1586-1591.

McBride M.B. (1994) Organic pollutants in soil. Pp. 
342-393 in: Environmental Chemistry of Soils. Oxford University Press, Oxford.

McBride M.B. (1997) A critique of diffuse double layer models applied to colloid and surface chemistry. Clays and Clay Minerals, 45, 598-608.

McBride M.B. \& Baveye P. (2002) Diffuse double-layer models, long-range forces, and ordering in clay colloids. Soil Science Society of America Journal, 66, 1207-1217.

McBride M.B. \& Mortland M.M. (1974) Copper (II) interactions with montmorillonite: evidence from physical methods. Soil Science Society of America Proceedings, 38, 408-415.

McBride M.B., Pinnavaia T.J. \& Mortland M.M. (1975a) Electron spin relaxation and the mobility of manganese(II) exchange ions in smectites. American Mineralogist, 60, 66-72.

McBride M.B., Pinnavaia T.J. \& Mortland M.M. (1975b) Electron spin resonance studies of cation orientation in restricted water layers on phyllosilicate (smectite) surfaces. Journal of Physical Chemistry, 79, 2430-2435.

Mclaren A.D. \& Peterson G.H. (1961) Montmorillonite as a caliper for the size of protein molecules. Nature 192, 960-961.

Mclaren A.D., Peterson G.H. \& Barshad I. (1958) The adsorption and reactions of enzymes and proteins on clay minerals: IV. Kaolinite and montmorillonite. Soil Science Society of America Proceedings, 22, 239-244.

Michaelian K.H. (1986) The Raman spectrum of kaolinite $\# 9$ at $21^{\circ} \mathrm{C}$. Canadian Journal of Chemistry, 64, 285-289.

Michot L.J., Villieras F., Francois M., Bihannic I., Pelletier M. \& Cases J.M. (2002) Water organisation at the solid-aqueous solution interface. Comptes Rendus Geoscience, 334, 611-631.

Mortland M.M. (1970) Clay-organic complexes and interactions. Advances in Agronomy, 22, 75-117.

Mortland M.M. (1984) Deamination of glutamic acid by pyridoxal phosphate- $\mathrm{Cu}^{2+}$ smectite catalysis. Journal of Molecular Catalysis, 27, 143-155.

Mortland M.M. \& Lawless J.G. (1983) Smectite interaction with riboflavin. Clays and Clay Minerals, 31, 435-439.

Murray H.H. (1954) Structural variations of some kaolinites in relation to dehydrated halloysite. American Mineralogist, 39, 97-108.

Naidja A., Violante A. \& Huang P.M. (1995) Adsorption of tyrosinase onto montmorillonite as influenced by hydroxyaluminum coatings. Clays and Clay Minerals, 43, 647-655.

Newman A.C.D. (1987) The interaction of water with clay mineral surfaces. Pp. 237-274 in: Chemistry of Clays and Clay Minerals (A.C.D. Newman, editor). Monograph 6, Mineralogical Society, London.

Noinville S., Revault M., Quiquampoix H. \& Baron
M.H. (2004) Structural effects of drying and rehydration for enzymes in soils: a kinetics-FTIR analysis of alpha-chymotrypsin adsorbed on montmorillonite. Journal of Colloid and Interface Science, 273, 414-425.

Norrish K. (1954) The swelling of montmorillonite. Discussions of the Faraday Society, 120-134.

Ockwig N.W., Greathouse J.A., Durkin J.S., Cygan R.T., Daemen L.L. \& Nenoff T.M. (2009) Nanoconfined water in magnesium-rich 2:1 phyllosilicates. Journal of the American Chemical Society, 131, 8155-8162.

Ogawa M. \& Kuroda K. (1995) Photofunctions of intercalation compounds. Chemical Reviews, 95, 399-438.

Olejnik S., Aylmore L.A.G., Posner A.M. \& Quirk J.P. (1968) Infrared spectra of kaolin mineral dimethylsulfoxide complexes. Journal of Physical Chemistry, 72, 241-249.

Olejnik S., Posner A.M. \& Quirk J.P. (1971) Infrared spectrum of the kaolinite-pyridine-N-oxide complex. Spectrochimica Acta Part A-Molecular And Biomolecular Spectroscopy, 27A, 2005-2009.

Parfitt R.L., Russell J.D. \& Farmer V.C. (1976) Confirmation of the surface structures of geothite (alpha-FeOOH) and phosphated goethite by infrared spectroscopy. Journal of the Chemical Society, Faraday Transactions 1, 72, 1082-1087.

Park C., Fenter P.A., Sturchio N.C. \& Nagy K.L. (2008) Thermodynamics, interfacial structure, and $\mathrm{pH}$ hysteresis of $\mathrm{Rb}^{+}$and $\mathrm{Sr}^{2+}$ adsorption at the muscovite (001)-solution interface. Langmuir, 24, 13993-14004.

Patil A.J. \& Mann S. (2008) Self-assembly of bioinorganic nanohybrids using organoclay building blocks. Journal of Materials Chemistry, 18, 4605-4615.

Pauling L. (1930) The structure of chlorites. Proceedings of the National Academy of Sciences, 16, 578-582.

Pauling L. (1960) The Nature of the Chemical Bond and the Structure of Molecules and Crystals: An Introduction to Modern Structural Chemistry, 3rd edition. Cornell University Press, Ithaca, New York, $644 \mathrm{pp}$.

Phambu N., Humbert B. \& Burneau A. (2000) Relation between the infrared spectra and the lateral specific surface areas of gibbsite samples. Langmuir, 16, 6200-6207.

Pimentel G.C. \& McClellan A.B. (1960) The Hydrogen Bond, 1st edition. W.H. Freeman and Co., San Fransisco, USA, 475 pp.

Pimentel G.C. \& McClellan A.L. (1971) Hydrogen bonding. Annual Review of Physical Chemistry, 22, 347-385.

Plançon A. (2001) Order-disorder in clay mineral structures. Clay Minerals, 36, 1-14. 
Plançon A. \& Tchoubar C. (1977a) Determination of structural defects in phyllosilicates by X-ray powder diffraction-I. Principle of calculation of the diffraction phenomenon. Clays and Clay Minerals, 25, 430-435.

Plançon A. \& Tchoubar C. (1977b) Determination of structural defects in phyllosilicates by X-ray powder diffraction-II. Nature and proportion of defects in natural kaolinites. Clays and Clay Minerals, 25, 436-450.

Plançon A., Giese R.F. \& Snyder R. (1988) The Hinckley index for kaolinites. Clay Minerals, 23, 249-260.

Poinsignon C., Cases J.M. \& Fripiat J.J. (1978) Electrical-polarization of water molecules adsorbed by smectites. An infrared study. Journal of Physical Chemistry, 82, 1855-1860.

Prost R. (1984) Low-temperature IR study of structrural $\mathrm{OH}$ groups of kaolinite, dickite and nacrite. Agronomie, 4, 403-406.

Prost R., Dameme A., Huard E. \& Driard J. (1987) Lowtemperature $(300-5 \mathrm{~K})$ IR study of structural $\mathrm{OH}$ groups of kaolinite, dickite, and nacrite. Pp. 17-23 in: Proceedings of the International Clay Conference. Denver 1985 (L.G. Schultz, H. Van Olphen \& F.A. Mumpton, editors) Clay Minerals Society, Boulder, Colorado, USA.

Quiquampoix H. \& Burns R.G. (2007) Interactions between proteins and soil mineral surfaces: Environmental and health consequences. Elements, 3, 401-406.

Quirk J.P. (2003) Comments on Diffuse double-layer models, long-range forces, and ordering of clay colloids. Soil Science Society of America Journal, 67, 1960-1961.

Rana K., Boyd S.A., Teppen B.J., Li H., Liu C. \& Johnston C.T. (2009) Probing the microscopic hydrophobicity of smectite surfaces. A vibrational spectroscopic study of dibenzo-p-dioxin sorption to smectite. Physical Chemistry, Chemical Physics, 11, 2976-2985.

Rao J.S., Dinadayalane T.C., Leszczynski J. \& Sastry G.N. (2008) Comprehensive study on the solvation of mono- and divalent metal cations: $\mathrm{Li}^{+}, \mathrm{Na}^{+}, \mathrm{K}^{+}$ $\mathrm{Be}^{2+}, \mathrm{Mg}^{2+}$ and $\mathrm{Ca}^{2+}$. Journal of Physical Chemistry A, 112, 12944-12953.

Ras R.H.A., Johnston C.T., Franses E.I., Ramaekers R., Maes G., Foubert P., De Schryver F.C. \& Schoonheydt R.A. (2003) Polarized infrared study of hybrid Langmuir-Blodgett monolayers containing clay mineral nanoparticles. Langmuir, 19, 4295-4302.

Ras R.H.A., Nemeth J., Johnston C.T., Dekany I. \& Schoonheydt R.A. (2004a) Infrared reflection absorption spectroscopy study of smectite clay monolayers. Thin Solid Films, 466, 291-294.

Ras R.H.A., Nemeth J., Johnston C.T., Dekany I. \&
Schoonheydt R.A. (2004b) Orientation and conformation of octadecyl rhodamine $\mathrm{B}$ in hybrid Langmuir-Blodgett monolayers containing clay minerals. Physical Chemistry, Chemical Physics, 6, $5347-5352$.

Ras R.H.A., Nemeth J., Johnston C.T., DiMasi E., Dekany I. \& Schoonheydt R.A. (2004c) Hybrid Langmuir-Blodgett monolayers containing clay minerals: effect of clay concentration and surface charge density on the film formation. Physical Chemistry, Chemical Physics, 6, 4174-4184.

Ras R.H.A., Schoonheydt R.A. \& Johnston C.T. (2007a) Relation between s-polarized and p-polarized internal reflection spectra: application for the spectral resolution of perpendicular vibrational modes. Journal of Physical Chemistry A, 111, 8787-8791.

Ras R.H.A., Umemura Y., Johnston C.T., Yamagishi A. \& Schoonheydt R.A. (2007b) Ultrathin hybrid films of clay minerals. Physical Chemistry, Chemical Physics, 9, 918-932.

Richter D.D. (2007) Humanity's transformation of Earth's soil: pedology's new frontier. Soil Science, 172, 957-967.

Rinnert E., Carteret C., Humbert B., Fragneto-Cusani G., Ramsay J.D.F. Delville, A., Robert J.L., Bihannic I., Pelletier M. \& Michot L.J. (2005) Hydration of a synthetic clay with tetrahedral charges: a multidisciplinary experimental and numerical study. Journal of Physical Chemistry B, 109, 23745-23759.

Rochester C.H. \& Topham, S.A. (1978) Infrared study of surface hydroxyl groups on goethite. Journal of the Chemical Society, Faraday Transactions 1, 75, 591-602.

Rotenberg B., Morel J.P., Marry V., Turq P. \& MorelDesrosiers N. (2009) On the driving force of cation exchange in clays: insights from combined microcalorimetry experiments and molecular simulation. Geochimica et Cosmochimica Acta, 73, 4034-4044.

Russell J.D. \& Farmer V.C. (1964) Infra-red spectroscopic study of the dehydration of montmorillonite and saponite. Clay Minerals Bulletin, 5, 443-464.

Russell J.D., Farmer V.C. \& Velde B. (1970) Replacement of $\mathrm{OH}$ by $\mathrm{OD}$ in layer silicates and identification of the vibrations of these groups in infra-red spectra. Mineralogical Magazine, 37, 869-879.

Russell J.D., Parfitt R.L., Fraser A.R. \& Farmer V.C. (1974) Surface structure of gibbsite, goethite and phosphated goethite. Nature, 248, 220-221.

Salles F., Devautour-Vinot S., Bildstein O., Jullien M., Maurin G., Giuntini J.C., Douillard J.M. \& Van Damme H. (2008) Ionic mobility and hydration energies in montmorillonite clay. Journal of Physical Chemistry C, 112, 14001-14009.

Salles F., Douillard J.M., Denoyel R., Bildstein O., Jullien M., Beurroies I. \& Van Damme H. (2009) 
Hydration sequence of swelling clays: evolutions of specific surface area and hydration energy. Journal of Colloid and Interface Science, 333, 510-522.

Schindler P.W., Furst B., Dick R. \& Wolf P.U. (1976) Ligand properties of surface silanol groups. Journal of Colloid and Interface Science, 55, 469-475.

Schlegel M.L., Nagy K.L., Fenter P., Cheng L., Sturchio N.C. \& Jacobsen S.D. (2006) Cation sorption on the muscovite (001) surface in chloride solutions using high-resolution X-ray reflectivity. Geochimica et Cosmochimica Acta, 70, 3549-3565.

Schoonheydt R.A. \& Johnston C.T., (2007) Surface and interface chemistry of clay minerals. Pp. 87-112 in: Handbook of Clay Science 1 (F. Bergaya \& B.K.G. Theng, editors) Elsevier Science Ltd, Amsterdam, The Netherlands.

Schramm L.L. \& Kwak J.C.T. (1982) Influence of exchangeable cation composition on the size and shape of montmorillonite particles in dilute suspension. Clays and Clay Minerals, 30, 40-48.

Servagent-Noinville S., Revault M., Quiquampoix H. \& Baron M.H. (2000) Conformational changes of bovine serum albumin induced by adsorption on different clay surfaces: FTIR analysis. Journal of Colloid and Interface Science, 221, 273-283.

Sheng G., Johnston C.T., Teppen B.J. \& Boyd S.A. (2002) Adsorption of dinitrophenol herbicides from water by montmorillonite. Clays and Clay Minerals, 50, 25-34.

Shinoda K.A.N. (1998) Interlayer proton transfer in brucite under pressure by polarized IR spectroscopy to $5.3 \mathrm{GPa}$. Physics and Chemistry of Minerals, 25, 197-202.

Shoval S., Yariv S., Michaelian K.H., Boudeulle M. \& Panczer G. (1999a) Hydroxyl-stretching bands 'A' and ' $Z$ ' in Raman and infrared spectra of kaolinites. Clay Minerals, 34, 551-563.

Shoval S., Yariv S., Michaelian K.H., Lapides I., Boudeuille M. \& Panczer G. (1999b) A fifth OHstretching band in IR spectra of kaolinites. Journal of Colloid and Interface Science, 212, 523-529.

Shoval S., Yariv S., Michaelian K.H., Boudeulle M. \& Panczer G. (2002) Hydroxyl-stretching bands in polarized micro-Raman spectra of oriented singlecrystal Keokuk kaolinite. Clays and Clay Minerals, 50, 56-62.

Sing K.S.W., Everett D.H., Haul R.A.W., Moscou L., Pierotti R.A., Rouquerol J. \& Siemieniewska T. (1985) Reporting physisorption data for gas solid systems with special reference to the determination of surface-area and porosity (Recommendations 1984). Pure and Applied Chemistry, 57, 603-619.

Sivozhelezov V., Pechkova E. \& Nicolini C. (2006) Mapping electrostatic potential of a protein on its hydrophobic surface: implications for crystallization of cytochrome P450scc. Journal of Theoretical Biology, 241, 73-80.
Spassov V.Z. \& Yan L. (2008) A fast and accurate computational approach to protein ionization. Protein Science, 17, 1955-1970.

Sposito G. (1984) The Surface Chemistry of Soils. Oxford University Press, New York, USA, 234 pp.

Sposito G. \& Prost R. (1982) Structure of water adsorbed on smectites. Chemical Reviews, 82, $553-573$.

Sposito G., Prost R. \& Gaultier J.P. (1983) Infrared spectroscopic study of adsorbed water on reducedcharge $\mathrm{Na} / \mathrm{Li}$ montrmorillonites. Clays and Clay Minerals, 31, 9-16.

Środoń J. \& McCarty D.K. (2008) Surface area and layer charge of smectite from CEC and EGME/ $\mathrm{H}_{2} \mathrm{O}-$ retention measurements. Clays and Clay Minerals, 56, $155-174$.

Stumm W. (1992) Chemistry of the Solid-Water Interface. Processes at the Mineral-Water and Particle-Water Interface in Natural Systems, $1^{\text {st }}$ edn. John Wiley \& Sons Inc., New York, USA, 428 pp.

Sun X.H. \& Doner H.E. (1996) An investigation of arsenate and arsenite bonding structures on goethite by FTIR. Soil Science, 161, 865-872.

Sutton R. \& Sposito G. (2001) Molecular simulation of interlayer structure and dynamics in $12.4 \AA \mathrm{Cs}-$ smectite hydrates. Journal of Colloid and Interface Science, 237, 174-184.

Swenson J., Bergman R. \& Howells W.S. (2000) Quasielastic neutron scattering of two-dimensional water in a vermiculite clay. Journal of Chemical Physics, 113, 2873-2879.

Szabo T., Szekeres M., Dekany I., Jackers C., DeFeyter S., Johnston C.T. \& Schoonheydt R.A. (2007) Layerby-layer construction of ultrathin hybrid films with proteins and clay minerals. Journal of Physical Chemistry C, 111, 12730-12740.

Tanford C. \& Wagner M.L. (1954) Hydrogen ion equilibria of lysozyme. Journal of the American Chemical Society, 76, 3331-3336.

Teppen B.J. \& Miller D.M. (2006) Hydration energy determines isovalent cation exchange selectivity by clay minerals. Soil Science Society of America Journal, 70, 31-40.

Theng B.K.G. (1974) The Chemistry of Clay-Organic Reactions, John Wiley and Sons, New York, USA, 343 pp.

Thompson J.G. (1985) Interpretation of solid state ${ }^{13} \mathrm{C}$ and ${ }^{29} \mathrm{Si}$ nuclear magnetic resonance spectra of kaolinite intercalates. Clays and Clay Minerals, 33, $173-180$.

Thompson J.G. \& Cuff C. (1985) Crystal structure of kaolinite:dimethylsulfoxide intercalate. Clays and Clay Minerals, 33, 490-500.

Tonle I.K., Diaco T., Ngameni E. \& Detellier C. (2007) Nanohybrid kaolinite-based materials obtained from the interlayer grafting of 3-aminopropyltriethoxysi- 
lane and their potential use as electrochemical sensors. Chemistry of Materials, 19, 6629-6636.

Umemura Y., Yamagishi A., Schoonheydt R., Persoons A. \& De Schryver F. (2002) Langmuir-Blodgett films of a clay mineral and ruthenium(II) complexes with a noncentrosymmetric structure. Journal of the American Chemical Society, 124, 992-997.

Venyaminov S.Y. \& Prenderast F.G. (1997) Water $\left(\mathrm{H}_{2} \mathrm{O}\right.$ and $\mathrm{D}_{2} \mathrm{O}$ ) molar absorptivity in the $1000-4000 \mathrm{~cm}^{-1}$ range and quantitative infrared spectroscopy of aqueous solutions. Analytical Biochemistry, 248, 234-245.

Viani B.E., Low, P.F. \& Roth C.B. (1983) Direct measurement of the relation between interlayer force and interlayer distance in the swelling of montmorillonite. Journal of Colloid and Interface Science, 96, 229-244.

Violante A., de Cristofaro A., Rao M.A. \& Gianfreda L. (1995) Physicochemical properties of protein-smectite and protein- $\mathrm{Al}(\mathrm{OH})_{(\mathrm{x})}$-smectite complexes. Clay Minerals, 30, 325-336.

Wada K. (1967) A study of hydroxyl groups in kaolin minerals utilizing selective-deuteration and infrared spectroscopy. Clay Minerals, 7, 51-61.

Walsh M.A., Schneider T.R., Sieker L.C., Dauter Z., Lamzin V.S. \& Wilson K.S. (1998) Refinement of triclinic hen egg-white lysozyme at atomic resolution. Acta Crystallographica Section D-Biological Crystallography, 54, 522-546.

Wang J.W., Dauter M., Alkire R., Joachimiak A. \& Dauter Z. (2007) Triclinic lysozyme at $0.65 \AA$ resolution. Acta Crystallographica Section D-Biological Crystallography, 63, 1254-1268.

Wang S.L. \& Johnston C.T. (2000) Assignment of the structural $\mathrm{OH}$ stretching bands of gibbsite. American Mineralogist, 85, 739-744.

Weissmahr K.W., Haderlein S.B. \& Schwarzenbach R.P. (1997) In situ spectroscopic investigations of adsorption mechanisms of nitroaromatic compounds at clay minerals. Environmental Science \& Technology, 31, 240-247.

Weissmahr K.W., Haderlein S.B. \& Schwarzenbach R.P. (1998) Complex formation of soil minerals with nitroaromatic explosives and other pi-acceptors. Soil Science Society of America Journal, 62, 369-378.

Wiewióra A., Wieckowski T. \& Sokolowska A. (1979) The Raman spectra of kaolinite sub-group minerals and of pyrophyllite. Archiwum Mineralogiczne, 35, $5-14$.

Wilding L.P. \& Lin H. (2006) Advancing the frontiers of soil science towards a geoscience. Geoderma, 131, 257-274.

Xu W., Johnston C.T., Parker P. \& Agnew S.F. (2000) Infrared study of water sorption on $\mathrm{Na}-, \mathrm{Li}-, \mathrm{Ca}-$ and Mg-exchanged (SWy-1 and SAz-1) montmorillonite. Clays and Clay Minerals, 48, 120-131.

Zhu D.Q., Herbert B.E., Schlautman M.A., Carraway E.R. \& Hur, J. (2004) Cation-\{pi\} bonding: a new perspective on the sorption of polycyclic aromatic hydrocarbons to mineral surfaces. Journal of Environmental Quality, 33, 1322-1330.

Zielke R.C., Pinnavaia T.J. \& Mortland M.M. (1989) Adsorption and reactions of selected organic-molecules on clay mineral surfaces. Pp. 81-98 in: Reactions and Movement of Organic Chemicals in Soils (B.L. Sawhney \& K. Brown, editors). SSSA Special Publication No. 22. Soil Science Society of America, Madison, Wisconsin, USA. 